\title{
State-of-the-art enantioseparations of natural and unnatural amino acids by high- performance liquid chromatography
}

István Ilisz ${ }^{1}$, Antal Péter ${ }^{1}$, Wolfgang Lindner ${ }^{2}$

${ }^{1}$ Department of Inorganic and Analytical Chemistry, University of Szeged, Dóm tér 7, H-6720 Szeged, Hungary

${ }^{2}$ Department of Analytical Chemistry, University of Vienna, Währinger Strasse 38, 1090 Vienna, Austria

\section{Keywords:}

enantioseparation; $\alpha$-, $\beta$ - and $\gamma$-amino acids; $N$-tagged amino acids; chiral stationary phases; high-performance liquid chromatography

\section{Corresponding author:}

Prof. Wolfgang Lindner

Department of Analytical Chemistry, University of Vienna

Währinger Strasse 38

1090 Vienna, Austria

e-mail: wolfgang.lindner@univie.ac.at

Fax: +43-2243-37 81914 


\section{Abbreviations}

AA, amino acid; Ac, acetyl; AcOH, acetic acid; ADAM, 1-aminoadamantane; AQC (AccQ-Tag), 6-aminoquinoyl- $N$-hydroxysuccinimidyl carbamate; BA, butylamine; $t$-Boc, $t$-butyloxycarbonyl; BSA, bovine serum albumin-based CSP; Bz, benzoyl; CAD, corona discharge detector; CBZ (Z), benzyloxycarbonyl; CD, cyclodextrin; CLEC, chiral ligand-exchange chromatography; CSP, chiral stationary phase; $R(-)-D B D-P y N C S, \quad R(-)-4-(3-i s o t h i o c y a n a t o p y r r o l i d i n-1-y l)-7-(N, N-$ dimethylaminosulfonyl)-2,1,3-benzoxadiazole; DCT, dichloro-s-triazine; 3,5-DCIB， 3,5dichlorobenzoyl; DEA, diethyl amine; 2D-HPLC, two dimensional HPLC; 3,5-DNB, 3,5dinitrobenzoyl; DNP, 2,4-dinitrophenyl; Dns, dansyl; EA, ethylamine; ELSD, evaporative light scattering detector; Exc/Em, excitation/emission wavelength; EtOH, ethanol; FA, formic acid; Fl, fluorescence detection; FLEC, (+)-1-(9-fluorenyl)ethyl chloroformate; FMOC, 9fluorenylmethyl-chloroformate; FP, succinimidyl ferrocenyl propionate; GITC, 2,3,4,6-tetra-Oacetyl- $\beta$-D-glycopyranosil isothiocyanate; HFBA, heptafluorobutyric acid; HPLC, highperformance liquid chromatography; IBLC, $N$-isobutyryl-L-cysteine; LOD, limit of detection; LOQ, limit of quantitation; Marfey reagent (FDAA, MR, FDNP-L-Ala-NH 2 ), 1-fluoro-2,4dinitrophenyl-5-L-alanine amide; $\mathrm{MBIC},(R)$-methyl benzyl isothiocyanate; MeCN, acetonitrile; MCT, monochloro-s-triazine; MQD, O-9-[2-(methacryloyloxy)-ethylcarbamoyl]10,11dihydroquinidine; MS, mass-spectrometry; NAC, $N$-acetyl-L-cysteine; Nap-Btz, $(S)-1-[\mathrm{H}-$ benzo(d) (1,2,3)triazol-1-yl)-2[6-methoxynaphthalen-2-yl-propan-1-one]; NBD-Cl, 7-chloro-4nitro-2,1,3-benzoxadiazole; NBD-F, 4-fluoro-7-nitro-2,1,3-benzoxadiazole; NBD-PyNCS, 4-(3isothiocyanatopyrrolidin-1-yl)-7-nitrobenzofurazan; $\quad$ NEIC,$\quad(S)$-1-(1-naphthyl) ethyl isothiocyanate; $(S)$-NIFE, (S)-N-(4-Nitrophenoxycarbonyl)phenylalanine methoxyethyl ester; $N$ NPTH, $N$-naphthoyl; $(S)$-OBS, $O$-benzyl- $(S)$-serine; OPA, $o$-phthalaldehyde; L-PGA-OSu, Lpyroglutamic acid succinimidyl ester; L-PGA[d(5)]-OSu, isotopic variant of L-pyroglutamic acid 
succinimidyl ester; Phg, phenylglicine; PA, propylamine; $N$-PTH, $N$-phthaloyl; QD, quinidine; QN, quinine; QN-AX and QD-AX, $t$-butyl carbamoylated QN and QD CSPs; L-STC, $(S)$-trityl-Lcysteine; TAHS, $p$ - $N, N, N$-trimethylammonioanilyl $N$ '-hydroxysuccinimidyl carbamate iodide; TBA, tributylamine; TEA, trimethylamine; TEAA, triethylammonium acetate; $N$-TCPHT, $N$ tetrachlorophthaloyl; TFA, trifluoroacetic acid; THF, tetrahydrofuran; TPA, tripropylamine; UHPLC, ultra-high-performance liquid chromatography; ZWIX $(+)^{\mathrm{TM}}$, sulfocyclohexyl carbamoylated QN-based zwitterionic CSP; ZWIX(-) ${ }^{\mathrm{TM}}$, sulfocyclohexyl carbamoylated QDbased zwitterionic CSP 


\begin{abstract}
This review discusses recent publications on the separation and analysis of natural and unnatural amino acid enantiomers by liquid chromatography. Focus is placed on methodological aspects relating chiral stationary phases and chiral columns which can cope with the challenge. Conceptually, amino acids can be enantioseparated in free form, which refers to the resolution of polar ampholytes, or as $\mathrm{N}$-protected amino acids, which can be regarded as acidic commodities. Such synthons are used, for instance, in peptide synthesis protocols. Amino groups are frequently tagged with highly fluorescent or MS/MS active labels in order to generate sensitive and simultaneously stereoselective assays of diverse amino acids in complex matrices.

It is our intention to present the state of the art of enantioselective amino acid analysis by HPLC concepts and to pinpoint practical aspects.
\end{abstract}




\section{Introduction}

Chirality caused by molecular asymmetry has special effects on physical, chemical, biological and pharmacological properties appearing at a molecular level. Amino acids (AAs), and carbohydrates (sugars), and the peptides, proteins, glycoproteins, polysaccharides etc. composed of such chiral building blocks are stereochemically defined. In biological systems, chiral entities (e.g. receptors) often display different biologically relevant responses to the enantiomers of chiral compounds such as drugs, agrochemicals, food additives, fragrances, etc., and also natural compounds including the D- and L-enantiomers of proteinogenic and non-proteinogenic amine acids (AAs).

As a result of the awareness of the importance of stereoselective bioactivity phenomena such as pharmacodynamics and pharmacokinetics, a strong demand has arisen in life and pharmaceutical sciences for efficient tools with which to separate the individual stereoisomers of a large body of chiral compounds per se, but also in trace amounts in biological matrices.

At an analytical level, liquid-phase separation techniques [liquid chromatography (LC) and capillary electrophoresis (CE)] are currently most widely applied; high-performance LC (HPLC) and supercritical fluid chromatography (SFC) have become very popular, though CE is also very powerful analytical technology [1,2]. For preparative enantiomer separations, HPLC and particularly SFC are the methods of choice [3]. Gas chromatography (GC) provides highly efficient enantioselective analysis systems for compounds which fulfill specific chemical requirements. Very useful GC separation systems exist for fully derivatized AAs [4]. However, the subject of this review rather a critical overview of publications of the last 5 years dealing with LC methodologies for the stereoselective resolution of AAs and some peptides.

Various strategies have been developed for the differentiation of enantiomers by chromatography: (i) indirect methods involving derivatization of a mixture of target enantiomers 
by a chiral derivatizing agent (CDA) and the generation of diastereomeric compounds which are physicochemically different and should therefore be chromatographically resolvable on achiral chromatographic columns; (ii) direct methods in which chiral mobile phase additives are used together with standard achiral stationary phases; and (iii) direct methods in which chiral separations are achieved by using a chiral stationary phase (CSP). The direct methods are based on the intermediate formation of diastereomeric associates between the chiral selector (SO) moiety and the two enantiomers of the chiral analytes, the selectands (SAs). When the stability constants of the two diastereomeric associates, symbolized by $[(R)-\mathrm{SO} \leftrightarrow(R)-\mathrm{SA}]$ and $[(R)-\mathrm{SO}$ $\leftrightarrow(S)$-SA], are sufficiently different from each other, direct enantioseparation can be achieved. In order to stabilize such associates, multiple intermolecular interactions between the SO and the SAs must come into play.

Over the years, HPLC and SFC with diverse types of CSPs have become the preferred methodologies to resolve mixtures of enantiomers and racemates. Where applicable, GC remains a powerful analytical tool for chiral separations due to the exceptionally high efficiency. For preparative enantiomer separations, HPLC and SFC are increasingly more often the method of choice thanks to a number of convincing arguments often associated with "green chemistry" $[3,5]$.

This review discusses only the status and recent developments in the analytical separation of enantiomers of free and $\mathrm{N}$-derivatized (tagged) natural and unnatural AAs, focusing on the direct HPLC methods. A recent review concentrated on indirect AAs-enantioseparations [4].

As depicted in Scheme 1, the structural variability of AAs is quite high, in view of $(i) \alpha$-, $\beta$ - and $\gamma$-AAs, (ii) cyclic AAs, (iii) constraint AAs and (iv) structural isomers, including the insertion of an additional chiral center besides the one to which the amino group is attached to. Further, it 
should be emphasized that AAs are ampholytes bearing at least one basic amino group and one acidic carboxylic group. For more detailed chemical structural information, we refer to the specific literature, which is massive.

Due to the intrinsically available free primary and/or secondary amino group and the carboxyl group of free AAs, these functionalities can be targeted by specific derivatization, labeling or tagging reactions. In peptide chemistry, $N$-protected AAs are most often dealt with $t$ butyloxycarbonyl (Boc), 9-fluorenylmethyl-chloroformate (Fmoc) and benzyloxycarbonyl (Cbz

or Z) as the most popular protecting groups. Under specific conditions, these protecting groups can be cleaved off without affecting the chemical structure of the peptide backbone. For analytical purposes, the Fmoc group and other tagging reagents and groups are commonly employed, some of which are listed in Scheme 2. In this context, those agents are of particular interest that exhibit a sensitive fluorescence and/or mass spectrometry (MS) signal.

\section{Indirect methods of amino acid enantiomer separation}

The use of CDAs to form diastereomeric derivatives of AAs that can be separated on achiral columns was introduced the early 1970s. Indirect separations require SA functional groups that are easily derivatizable; in the case of AAs, this is preferentially an amino group. The reaction with a CDA should be fast and nonstereoselective; a difference in the rates of formation of the diastereomers may otherwise cause a kinetic resolution which would eventually lead to false quantitative results. Consequently, it is essential that the chiral derivatization proceeds quantitatively for both enantiomers, and racemization does not occur on any of the chiral centers of the CDA, SA or the diastereomeric derivatives. Besides the low cost of the achiral stationary phase, the relatively facile method development, the favorable chromatographic properties [higher sensitivity the lower limit of detection (LOD)] and the better resolution after the 
derivatization of AAs are advantages of indirect methods. However, the increased efforts to be taken in consideration for method validation may be cumbersome. Since a fair number of CDAs are commercially available in both enantiomeric forms, the elution sequence can be changed, i.e. the peak of the enantiomeric impurity can be eluted before the main peak, with the result of easier quantification. The reactions of the amino group of the AAs are mainly involve the formation of amides, carbamates, ureas and thioureas. Information on this subject may be found in numerous reviews [4,6-10]. Recent relevant publications are detailed in Table 1.

\section{Recent applications}

Diastereomeric derivatives of amino alcohols and nonproteinogenic AAs with $(S)-N-(4-$ nitrophenoxycarbonyl)phenylalanine methoxyethyl ester $[(S)-\mathrm{NIFE}]$ have been analyzed by reversed-phase (RP)-HPLC [11]. Validation demonstrated that the method can be utilized for pharmaceutical applications. The derivatization conditions were optimized for the reaction between $o$-phthalaldehyde (OPA) and $N$-isobutyryl-L-cysteine (IBLC) reaction and for the analyses of $\beta$-amino acidsAAs [12]. Test of the validated method in cell extract samples gave 25 pmol as the limit of quantification (LOQ). It can be pointed out that ultrahigh-performance liquid chromatography (UHPLC) can be performed more easily for the indirect than for the direct approach, which typically lacks the corresponding UHPLC column technology; however, this situation will probably change in the near future. An indirect RP-HPLC method developed and validated for the analysis of L-cycloserine in bulk D-cycloserine was based on derivatization with OPA and $N$-acetyl-L-cysteine $f(\mathrm{NAC})$ [13]. The optimized method proved sufficiently robust for application in routine quality control in pharmaceutical analyses. SNaproxen based CDAs were applied for different model compounds by Bhushan et. at. Phthalimidyl-(S)-naproxen has been used to separate the enantiomers of selenomethionine [14], and $(S)$-naproxen-benzotriazole (NapBtz) to separate the enantiomers of different proteinogenic AAs [15,16]. Isothiocyanate based 
CDAs, $(R)$-Methyl benzyl isothiocyanate (MBIC) and (S)-1-(1-naphthyl)ethyl isothiocyanate (NEIC) were used by the same research group to separate the enantiomers of selenomethionine [17], while proteinogenic AAs were derivatized with cyanuric chloride-based reagents [18-20]. Higher stability of the diastereomers, enhanced resolution and a lower limit of detection (LOD) were generally achieved in comparison with earlier-described methods.

\section{Direct methods of separation of structurally diverse amino acid enantiomers}

Direct chromatographic methods of enantiomer separation on CSPs have undoubtedly taken over in recent years. Direct enantioseparation generally has the advantages that $i$ ) the chiral impurity in the SO molecules bound to the chromatographic support material is not critical, but its content should be controlled for the sake of reproducible stereoselectivity of the prepared CSPs, ii) partial racemization of the $\mathrm{SO}$ of the CSP is very unlikely as long as the chromatographic conditions are reasonable, iii) there is no reagent excess that could interfere with the detection or worsen deteriorate the chromatographic resolution in the analysis of free AAs (the issue of excess reagent peaks remains in the case of AA tagging), and iv) scaling-up for preparative purposes on chromatographic columns is readily achievable and can become relevant, e.g. in the fine chemical production of $N$-protected AA commodities with very high enantiomeric purity.

However, AA-type SAs are often derivatized (tagged) with nonchiral reagents in order to modify the analytes so that the enantiomers can be better separated on the CSPs and/or become more sensitive for detection. Naturally, partial racemization of the analyte must be avoided in such cases. It should be emphasized that the concept of non-chiral derivatization preferentially of the amino group can often lead to a win-win-situation as on the one side the enantioselective molecular recognition process with a given CSP can be supported and on the other side also the detection sensitivity and selectivity can be strongly enhanced. 
These aspects are particularly emphasized throughout this paper. We argument focus especially more specifically on publications in which commercially available CSPs are used, making this review useful from practical aspects. Promising, though not yet commercialized CSPs are naturally also included.

This main section discusses the direct resolution of free (nontagged) AAs, the stereoselective resolution of tagged AAs and applications, particularly for complex sample matrices.

\subsection{CSPs frequently applied for the enantioseparation of free amino acids}

Comprehensive information on recent articles is presented in Table 2. This section relates particularly to the most promising and frequently employed CSPs.

\subsubsection{Macrocyclic glycopeptide-based chiral stationary phases}

Unlike other classes of SOs, macrocyclic antibiotics display a large variety of structural types. In general, these compounds have molecular masses in the interval 600-2200. There are acidic, basic and neutral types, and they often contain aromatic groups. These favorable characteristics of SOs allow them to interact with AAs of different types, taking advantage of the basket-like three-dimensional structures of the SOs in combination with diverse H-bonding and hydrophobic interaction sites derived from the intrinsic peptidic structure elements. The concept of using macrocyclic antibiotics as CSPs was introduced by Armstrong in 1994 [21] and their usefulness in AA resolutions has since been amply proven. The commercially available glycopeptide-based CSPs for HPLC are related to teicoplanin, teicoplanin aglycon, vancomycin, vancomycin aglycon and ristocetin A. However, Staroverov et al. used similar macrocyclic antibiotic-type SO (eremomycin) for AA analyses [22].

Recent applications 
Teicoplanin and teicoplanin aglycon-containing CSPs have been successfully applied for the enantiomeric separation of synthetic monoterpene-based 2-aminocarboxylic acids [23]. Mechanistic aspects of the chiral recognition process have been discussed with respect to the structures of the analytes. Similarly, the effects of the separation conditions and temperature on the enantioselective resolution of isoxazoline-fused 2-aminocyclopentanecarboxylic acids [24] and bicyclo[2.2.2] octane-based 2-amino-3-carboxylic acids [25] have been studied on different macrocyclic glycopeptide-based (Chirobiotic) columns. Apparent thermodynamic parameters have been calculated, and entropically- and enthalpically-driven separations discussed as part of the molecular recognition process. The enantioresolutions of free unusual AAs and constraint $\beta$ AAs on teicoplanin- and polysaccharide-based columns have been compared [26,27]. The optimized methods proved applicable for enantiomeric purity (enantiomeric excess, ee) control. [27]. The unexpected and extraordinarily high selectivity and resolution obtained for these free constraint AAs on a polysaccharide-based column ensures suitability for preparative purposes.

A selection of 19 pairs of free $\alpha$-AAs and 6 pairs of free dipeptides were applied to test the efficiency of macrocyclic antibiotic-based SOs covalently attached to fully or superficially porous silica particles [28]. The results were compared with the enantioresolutions achieved on commercialized (Chirobiotic and cyclofructan-based Larihc) columns. With the same mobile phase, the superficially porous particle-based CSP provided the greatest efficiency and shortest analysis time. In some cases, ultrafast chiral separations could be realized in seconds. Examples of acidic or basic free AAs have not been reported. LC-MS applications are generally well feasible.

\subsubsection{Crown ether-based chiral stationary phases}


Chiral crown ethers with a cavity of specific size and with chiral structure elements of macrocyclic polyethers with repeating $-\mathrm{O}-\mathrm{C}_{2} \mathrm{H}_{4}$ - units, where the oxygen atoms can serve as electron donors, serve as the SO moieties. Inorganic and alkylammonium cations can be incorporated into such a cavity. Unlike in cyclodextrins (CDs) where the host-guest complexation is based on hydrophobic SO-SA interactions, in crown ethers the inclusion complexation is based mainly on multiple $\mathrm{H}$-bonding between the $\mathrm{H}$ atoms of the ammonium group of the $\mathrm{SAs}$ and the $\mathrm{O}$ atoms of the polyether of the SO. Enantioselective recognition is accomplished via additional intermolecular interactions of the substituents of the chiral SO and SA moieties. As a consequence, chiral crown ethers can be used to resolve enantiomers containing a protonated primary amine functional group which acquires requires a low $\mathrm{pH}$ of the mobile phase (typically $\mathrm{pH}$ around 2-3). The mobile phase conditions are in many cases unfavorable for MS detection. For AAs with a secondary amino function, enantioselective resolution usually fails.

\section{Recent applications}

A (+)-(18-crown-6)-2,3,11,12-tetracarboxylic acid-based CSP was utilized for the enantioseparations of $\beta^{2}$-amino acids [29] and isoxazoline-fused 2-aminocyclopentanecarboxylic acids [30]. The effects of the mobile phase composition, the $\mathrm{pH}$, the concentration and the nature of the modifiers were investigated and discussed. CSPs based on (3,3'-diphenyl-1,1'-binaphthyl)20-crown-6 were found to be useful for the resolution of the enantiomers of vigabatrin and its analog $\gamma$-AAs [31] and of valacyclovir and its analogs [32].

\subsubsection{Ligand exchange-based chiral stationary phases}

Introduced by Davankov and Rogozhin [33], chiral ligand-exchange chromatography (CLEC) for the direct separation of free $\alpha$-AA enantiomers is based on the formation of diastereomeric mixed 
chelate complexes though use of a chiral chelating agent, mainly derived from an $\alpha$-AA together with a transition metal ion [most frequently copper(II), nickel(II), or zinc(II)] as SO. This can be carried out via a mobile phase additive of the SO or via an immobilized SO with chelating properties.

Numerous CLEC CSPs have been applied so far with different SO motifs, most often prolinetype AA derivatives. The retention and separation are strongly affected by the concentrations and natures of the mobile phase components, together with other variables, such as $\mathrm{pH}$ and temperature. As the mobile phase must contain a certain amount of the metal ion in the form of a salt plus a buffer, this enantiomer separation methodology, although highly stereoselective, is not well applicable for LC-MS.

\section{Recent applications}

As an interesting variant $O$-benzyl- $(S)$-serine $[(S)$-OBS $)]$ was applied as SO for the chiral discrimination of racemic AAs [34]. Computational modeling was utilized to shed light on the network multitude of interactions and perturbations that can play a relevant role in the enantioselective molecular recognition and retention process. Analogs of isoxazoline-fused aminocyclopentanecarboxylic acids were enantioseparated on a sodium $N-((R)$-2-hydroxy-1phenylethyl)- $N$-undecylaminoacetate-based column [35]. The calculated thermodynamic parameters suggested that the trans analogs induce more efficient binding to the $\mathrm{SO}$, as reflected by the larger negative free energies. In an application-oriented paper, the D-AA content of cheese samples was determined by CLEC by applying ( $S$ )-trityl-L-cysteine (L-STC) dynamically coated onto octadecylsilica [36]. To ensure food safety the combination of CLEC and conventional achiral chromatography was utilized to assess the impact of natural or artificial interventions on the product quality. 


\subsubsection{Zwitterionic ion-exchange-type chiral stationary phases}

A novel class of zwitterionic (ampholytic) chiral ion-exchange-type CSPs as chiral SO motif was recently introduced. These are based on a weak cationic site derived from the Cinchona alkaloid moiety quinine (QN) or quinidine (QD) (a weak anion exchanger, WAX) and an anionic site derived from a chiral trans-aminocyclohexanesulfonic acid molecule moiety (a strong cation exchanger, SCX) [37].

Free AAs are ampholytic in character; the number of bonds between the AA group components and hence the distance between the chargeable sites within the molecule vary between the $\alpha$-, $\beta$ and $\gamma$-AAs. As a consequence of the ampholytic properties, both the SO and SA ampholytes can undergo double ion pairing with each other due to the attractive electrostatic interactions of the charged and chargeable sites of the SO and SAs in a polar ionic (PI) or hydro-organic mobile phase environment.

Due to their nature, these ZWIX selectors allow the separation of the enantiomers of a remarkably broad spectrum of ionizable chiral analytes, ranging from acidic to basic and zwitterionic compounds as $N$-tagged, $O$-tagged or free AAs and small peptides. The occurrence of anionic, cationic and zwitterionic ion-exchange processes has been confirmed and these processes are predominantly involved in SO-SA interactions as part of the overall enantioselective retention and molecular recognition processes. Additional H-bonding and hydrophobic interactions are very likely to support the chiral recognition phenomena.

\section{Recent applications}

Free $\alpha$-, $\beta$ - and $\gamma$-AAs with different substitution patterns, including C-methylated $\alpha$-AAs, were enantioresolved by Cinchona alkaloid-based CSPs [38]. Through the application of slightly acidic polar organic (PO) and polar ionic (PI) mobile phases, fairly good enantioseparations 
could generally be achieved. The effects of structural variants of monoterpene-based $\beta$-AAs on the resolution were investigated [39]. The elution sequence was determined for all the investigated analytes, and was found to be opposite on the quinine QN-based ZWIX $(+)^{\mathrm{TM}}$ and the pseudoisomeric pseudoenantiomeric quinidine QD-based ZWIX(-) ${ }^{\mathrm{TM}}$ columns. (The Cinchona alkaloids QN and QD are diastereomers, but the configurations of the QN $(8 S, 9 R)$ and QD $(8 R, 9 S)$ molecular moieties and the resulting steric environment largely determine the chiral recognition abilities of these SOs, and ZWIX $(+)^{\mathrm{TM}}$ and ZWIX(-) ${ }^{\mathrm{TM}}$ are therefore frequently referred to as "pseudoenantiomers" because they behave as quasi-enantiomeric CSPs [38-40].) The same set of model compounds was applied to carry out a temperature dependence study [40]. Calculation of the apparent thermodynamic parameters revealed unusual temperature-induced retention behavior in some cases: the retention time increased with increasing temperature. HPLC methods were also developed for the enantioresolution of sixteen unusual $\beta^{2}$-AAs [41]. The mobile phases applied were found to support ionic interactions between the zwitterionic SOs and free, ampholytic AAs. Similar behavior was found for the resolution of bicyclo[2.2.2]octanebased aminocarboxylic acids [42]. Various AAs and their analogs were utilized to develop schemes for efficient generic screening methods for ZWIX ${ }^{\mathrm{TM}}$ columns [43]. Another study was conducted for the enantioseparation of 27 unusual cyclic secondary $\alpha$-AAs on QN- and QD-based CSPs [44]. For some applications, the QN- or the QD-based CSP appeared more suitable for the enantiomeric separations, which are SA-dependent, and relates to the fact that the SOs on ZWIX $(+)^{\mathrm{TM}}$ and ZWIX(-) ${ }^{\mathrm{TM}}$ CSPs are only pseudo-enantiomeric to each other. The calculated thermodynamic parameters were found to depend on the structures of the SAs and the SOs employed. Structure-selectivity relationships were investigated through the enantiomeric separations of isoxazoline-fused aminocyclopentanecarboxylic acids [45]. SAs with methyl substituents in most cases interacted more strongly than ethyl-substituted ones with the SO, 
which resulted in higher selectivity and resolution. This confirms the potentially strong effects of even small changes in the residues at a stereogenic center of the chiral SA. The performances of QN- and QD-based CSPs in separating $\beta^{2}$ - and $\beta^{3}$-AAs as model compounds revealed, that the QD-based column mostly exhibited better selectivity for both $\beta^{2}$ - and $\beta^{3}$-AAs [46]. The double ion pairing concept works more or less equally well for aminocarboxylic, -sulfonic and -phosphonic acids. Novel CSPs recently prepared through the coupling of a crown ether moiety to QN derivatives exhibited specific selectivity for chiral acidic SAs and for some free AAs [47]. From this example, it might be argued that the crown ether moiety acts as an interaction site for the protonated amino group of the AA, and the carboxylate group interacts with the charged quinuclidine moiety of QN.

Another interesting field of application of zwitterionic CSPs that may be expected to gain in importance in the near future is the stereoselective separation and analysis of small peptides [4851].

\subsection{Chiral stationary phases frequently applied for the enantioseparation of tagged amino acids}

As indicated above, a specific tagging (derivatization) of AAs preferentially on the amino group can lead to molecular species with better chromatographic properties as the highly polar ampholytes become less polar and only acidic, and can promote higher detection sensitivity.

Overall, such a strategy can result in higher enantioselectivity and/or lower LOQ. Information on recent relevant publications is provided in Table 3.

In this context, it should be remembered that the $N$-derivatization (tagging) of any AA results in acid-type SAs, offering new possibilities in the selection of suitable CSPs. The chemical 
structures of frequently used $\mathrm{N}$-protecting (tagging) nonchiral reagents are presented in Scheme 2.

\subsubsection{Resolution on polysaccharide-type chiral stationary phases}

To illustrate the long history of polysaccharide-based chiral separations, resolution of the enantiomers of some free AAs on cellulose as CSP in the form of paper chromatography was described in 1951 [52]. Polysaccharides, and especially amylose and cellulose, are naturally occurring polymers that can serve as the basis for the fabrication of more efficient and enantioselective CSPs by a dedicated derivatization of the free $\mathrm{OH}$ groups of the saccharide sub-

unit. In this context, cellulose and amylose derivative-related CSPs based on coated silica were first reported by Okamoto in 1984 [53]. These phases have subsequently become highly popular CSPs suitable for the resolution of a broad spectrum of chiral compounds comprising neutral, acidic and basic SAs. The recent introduction of immobilized polysaccharide-type CSPs, has markedly improved their chemical stability and hence their more flexible usage [54], as widely proven, particularly in the industrial environment. These chiral columns are also highly feasible for SFC applications. However, these phases are usually not the primary choice for free AAs.

\section{Recent applications focused on $\mathrm{N}$-derivatized amino acids}

Cellulose tris(3-chloro-4-methylphenylcarbamate) was recently applied as packing material for nano-LC and capillary electrochromatographic measurements [55]. The packed column was evaluated for the separation of Fmoc AA enantiomers, where 20 of 23 AA could be resolved. An HPLC method was also developed for the enantioresolution of $\alpha$-AA esters [56]. Of the commercially available polysaccharide-based CSPs provided by several suppliers, the covalently bonded Chiralpak IA and IC columns (Daicel) proved to be the preferred choice for the 
enantiodiscrimination of the investigated $\alpha$-AA esters. Interestingly, the $N$-naphthoyl ( $N$-NPTH), $N$-phthaloyl $(N$-PTH), $N$-tetrachlorophthaloyl $(N$-TCPHT) derivatives of AAs and their esters were well enantioresolved by polysaccharide-derived CSPs [57]. The interactions between the polymeric SO moieties and the SAs were described by computational modeling. Of numerous practical examples, the Boc derivatives of $\beta$-phenylproline strereoisomers were resolved on analytical and preparative scales on amylose- and cellulose-based CSPs [58]. These CSPs performed excellently for large-scale HPLC and SFC applications. All the applications described involved the use of mobile phases suitable for MS detection.

\subsubsection{Cyclodextrin-based (brush type) chiral stationary phases}

CDs are naturally occurring, nonreducing oligosaccharides. The most widely utilized $\alpha-, \beta$ - and $\gamma$ CD are composed of 6, 7 and 8 D-glucopyranose units bonded through $\alpha-1,4$ glycosidic linkages forming a toroidal, hollow, truncated cone shape. The exterior of the toroid is relatively hydrophilic because of the presence of 18, 21 and 22 hydroxy groups, while the internal cavity is much more hydrophobic, which favors the enantioseparation of partially nonpolar compounds via selective inclusion. The hydroxy groups of the CDs can be derivatized, so that a wide variety of modified CDs can be prepared. Thanks to their relatively simple production, natural and modified CDs have found various applications, and CD-based CSPs are among the more popular CSPs used in chiral analysis. Because of their solvent compatibility, they have the ability to operate in different modes of HPLC: RP, normal-phase (NP), PO and PI modes, i.e. they may be regarded as multimodal-type CSPs. However, the spectrum of enantioselectivity is more restricted than for other SO types as the inclusion complexation is a rather specific and residue size-dependent property. As a consequence, these CD-based CSPs for HPLC have somewhat lost in popularity in recent years. However, CDs are still widely used for CE applications [1,2]. 


\section{Recent applications}

A novel bilayer CD-based CSP was fabricated by a two-step click approach, in which a native CD (down layer) and a perphenylcarbamoylated CD (top layer) were introduced onto a silica surface [59]. The enantioseparation abilities of this CSP were tested with dansyl (Dns) AAs among others, and were found to be tunable by endowing functionality to one of the CD layers. A covalently bonded cationic CD-based CSP was prepared by thiol-ene click chemistry and tested on a set of chiral compounds involving dansyl Dns AAs [60]. A surface-up click approach was applied for the fabrication of a triazole-bridged bilayer CD-based CSP [61]. The as-prepared bilayer CSP afforded enhanced binding ability and enantioselectivity toward dansyl Dns AAs. It should be mentioned that an aryl group can be particularly well inserted into the hydrophobic cavity of the CD-based CSPs as compared with aliphatic residues.

\subsubsection{Pirkle-type (brush type) chiral stationary phases}

These CSPs were introduced by Pirkle and Sikkenga [62], who immobilized ( $R$ )-2,2,2-trifluoro1-(9-anthryl)ethanol on a silica support. Dinitrobenzoyl (DNB) derivatives of AAs and other racemates could be separated well. These phases became the first commercially available CSPs in the early 1980s. Mechanistically, they preferentially function in NP mode and the enantioselectivity is based on multiple $\mathrm{H}$-bonding, $\pi-\pi$ interactions and dipole-dipole stacking between the SO and the SAs. As a follow-up, synthetic chiral SOs with low molecular masses

and a $\pi$-acidic or $\pi$-basic and H-bonding character have been prepared and attached to solid supports in a brush-type format. In recognition of his pioneering work, they became known as Pirkle-type phases. As an option these CSPs are usually available in both enantiomeric forms, leading to the very important consequence that the elution sequence for two enantiomers can be 
switched by exchanging an $(R)$-SO-based CSP with an (S)-SO-based CSP. This is not possible for SOs from the natural chiral pool, such as polysaccharides, proteins and macrocylic antibiotics. Exceptions include AA-derived SOs and Cinchona alkaloid-based SOs, which exist as (pseudo)enantiomers as outlined above. The concept of enantiomeric "chiral columns" is of fundamental importance and is encountered for the pseudoenantiomeric ZWIX $(+)^{\mathrm{TM}}$ and ZWIX()$^{\mathrm{TM}}$ columns developed by Lindner et al. [37]. For the cyclodextrin, polysaccharide and macrocyclic antibiotics based CSPs such possibilities do not apply.

\subsubsection{Ion-exchange-based chiral stationary phases}

Ion-exchange-based CSPs are frequently applied for the resolution of variety of acids, including derivatized AAs [63]. They exist as weak anion-exchangers based on Cinchona alkaloids (QNAX, QD-AX columns) or as strong cation-exchangers based on trans-1,2aminocyclohexanesulfonic acid derivatives [64]. The ampholytic ZWIX-type CSPs likewise function in these modes (see above).

\section{Recent applications}

In order to evaluate the impact of the bonding chemistry on the overall enantioselectivity of a given SO unit, anion-exchange-type thioether-linked and triazole-linked CSPs were synthesized by click chemistry and evaluated with structurally diverse racemic acids, including $N$-protected [dinitrobenzoyl (DNB), benzoyl (Bz), acetyl (Ac) or Z] AAs [65]. Dinitrophenyl (DNP) and DNB derivatives of AAs were used to test the enantiorecognition abilities of QN-based CSPs $[66,67]$; the elution sequence was reversed for the DNP- relative to the DNB-tagged AAs. This clearly indicates a substantial difference of the stereoselective molecular recognition principle and the need to prove the elution sequence of a pair of enantiomers. To improve the UV detectability and to enhance the enantioselectivity, the AAs were also modified with 2- 
acyldimedone, and 12 structurally related compounds were investigated [68]. As a very favorable application, the QN- and QD-based CSPs were employed for the enantioresolution of fluorescent (6-aminoquinoyl- $N$-hydroxysuccinimidyl carbamate, AQC)-tagged AAs [69]. From systematic studies of the chiral and chemoselective recognition processes, it became evident that the ureatype tagging functionality supports the overall chiral recognition substantially and more universally. Essentially all AQC-tagged AAs could be resolved and also sensitively detected by MS/MS through use of a ZWIX-type column. Specifically an organic monolithic capillary column based on a QD derivative was prepared and applied for the enantioseparation of several $N$-derivatized [DNB, dichlorobenzoyl (DCIB), Fmoc, etc.] AAs [70]. 2,5-Dioxopyrrolidin-1-yl(2(6-methoxy-4-oxoquinolin-1(4H)-yl)ethyl) carbonate was designed for the pre-column derivatization of proteinogenic AAs [71]. The derivatives were analyzed on Chiralpak ${ }^{\mathrm{TM}} \mathrm{QN}-\mathrm{AX}$ and ZWIX $(+)^{\mathrm{TM}}$ with MS/MS detection. The simultaneous diastereo- and enantioseparation of $N^{\alpha}$-Boc- $N^{4}$-(hydroorotyl)-4-aminophenylalanine was investigated by applying ZWIX ${ }^{\mathrm{TM}}$ columns [72]. A molecular dynamics computational protocol was applied to gain a better understanding of the molecular basis of the retention mechanism. All the mobile phases used for the cation and anion-exchangers are well suited for MS detection.

\section{Chiral analyses of amino acids in biological matrices}

Determination of the enantiomeric distribution of various AAs in a range of biological matrices is a highly important task in life sciences. Information on recent publications is listed in Table 4.

\subsection{Indirect methods}

An LC-MS/MS method was developed and validated for the determination of D-serine in human plasma [73] based on pre-column derivatization with $(R)$-1-Boc-2-piperidine carbonyl chloride. 
The optimized method was applied for the analyses of plasma samples from patients receiving a 5-day intravenous infusion of ketamine. In another example, MS-based methods were developed and compared for the determination of the ee of proteinogenic AAs [74]. The enantiomers of Trp and kynurenine were separated by pre-column fluorescence derivatization with $R(-)-4-(3-$ isothiocyanatopyrrolidin-1-yl)-7-(N,N-dimethylaminosulfonyl)-2,1,3-benzoxadiazole [R(-)-DBDPyNCS] in rat plasma samples $[75,76]$. The experimental results led to the conclusion that the administered D-Trp was partially converted to L-Trp in vivo. A ultra high performance liquid ehromatography (UHPLC)-MS/MS method based on $R(-)$-DBD-PyNCS derivatization was developed for the simultaneous determination of partial AA racemization and isomerization of an $N$-terminal amyloid- $\beta$-peptide sequence [77]. The method was applied in the analysis of human brain tissues. In another relevant paper, the D-AA contents of human plasma, serum and urine samples were determined via OPA/IBLC derivatization and MS detection [78]. The method displayed excellent sensitivity (LOD at the pmol/L level) and it was claimed that no matrix effects or stability problems occurred. A distinction between D- and L-AAs from the broth of Streptomyces sp. was carried out by derivatization procedures using 2,3,4,6-tetra- $O$-acetyl- $\beta$-Dglycopyranosyl isothiocyanate (GITC) and 1-fluoro-2,4-dinitrophenyl-5-L-alanin amide (FDAA) prior to LC-MS assay [79]. Isotopic labeling combined with MS detection was applied for the quantification of DL-AAs from human serum samples [80]. The proposed method utilizing Lpyroglutamic acid succinimidyl esters (L-PGA-OSu) as derivatizing agents seemed to be applicable not only for biological samples, but also for food products. A method based on chiral derivatization was developed for the enantiodiscrimination of AAs from body fluids [81]. In a comparison 7 different CDRs, (S)-NIFE offered the best performance in terms of selectivity and sensitivity. This selection of examples reveals that the indirect methodology is not obsolete for the analysis of real-world samples. 


\subsection{Direct methods}

Conceptually, these methods also most often integrate a derivatization strategy, but with the use of nonchiral reagents. In this context, an analytical procedure using model peptides was established to discriminate the innate D-Ala and D-Phe generated during the common acidhydrolysis of peptides (proteins) through LC-MS/MS detection and a Chirobiotic TAG ${ }^{\mathrm{TM}}$ column [82]. The developed method was expected to be applicable for the determination of other AAs too.

Very significant contributions from the application of AA fluorescent tagging protocols emerged from the work of Hamase et al. who used 4-fluoro-7-nitro-2,1,3-benzoxadiazole (NBD-F) as labeling agent and the sample analysis by a two-dimensional (2D) LC system [83-88]. NBD-FAAs were separated on an RP column in the first dimension, and the collected fractions containing the peaks of the respective NBD-AAs were then introduced into an enantioselective column representing the second dimension, where the D and L enantiomers of the NBD-AAs could be baseline-resolved. The enantioselectivity was preferentially accomplished on Pirkle-type columns, but chiral ion-exchange systems were also suitable.

In the course of specific applications, the developed 2D-HPLC system based on NBD-F tagging was applied for the analysis of AAs of different biological origins. Similarly as in the above mentioned method, a 2D-HPLC system was used for the analysis of AAs from mice tissues with a Chiralpak ${ }^{\mathrm{TM}}$ QD-AX column [89]. Good peak shapes, good selectivities and high resolution power were achieved. A 1D chromatographic method was also described for the analysis of proteinogenic AAs on anion exchange-type chiral columns [90]. Similar results were attained with hydroxy succinimidyl ferrocenyl propionate (SFP) as tagging reagent. The enantioselectivity was sufficient for most of the proteinogenic AA derivatives. It was recently shown that $p-N, N, N-$ 
trimethylammonioanilyl $N^{\prime}$-hydroxysuccinimidyl carbamate iodide (TAHS) or AQC (AccQ) (see Scheme 2) derivatized AAs could be separated well on ZWIX phases with excellent sensitivity in an LC-MS mode [91]. The method was successfully applied for the analyses of AAs in rat plasma and tissue samples.

Another group analyzed the level of D-serine in the mouse brain by using a chiral crown ether column and an HPLC-MS/MS system [92]. The proposed surrogate analyte method provided quantitative data with good accuracy and precision without pre-column derivatization.

For a dedicated enantioselective single AA analysis, 1D LC-MS/MS systems may be sufficient. However, it is very likely that the simultaneous and sensitive determination of several pairs of AA enantiomers in complex matrices can be solved only by a tagging strategy involving a 2D-LC system in combination with fluorescence and/or MS/MS detection.

\section{Conclusions}

The accurate and sensitive analysis of the individual enantiomers of natural (proteinogenic and nonproteinogenic) but also unusual AAs remains an important and challenging field in the life sciences, but also in pharmaceutical product analysis, etc. In this context, the following main subjects of enantioselective AA analysis have been addressed:

1. The chemical analysis of synthetic AA-type products and their characterization in terms of enantiomeric purity. This includes the individual $N$-protected AA building blocks for peptide synthesis, etc.

2. The analysis of biological samples (blood, serum, urine, tissue, etc.) for the levels of individual D-AAs besides the large excess of L-AAs in these matrices. Such data could be of diagnostic value, for instance, as early disease markers. 
3. D-AAs may occur in proteins as "markers" of aging due to in vivo racemization. The hydrolyzates of proteins may therefore contain biologically relevant information based on the content of proteinogenic D-AAs amine acids.

4. Proteinogenic and also many nonproteinogenic AAs found in D- and L-form in food and feed stuffs may have physiological effects, and investigations of the individual enantiomers will therefore certainly be of significance.

5. Analysis of the metabolomic profile regarding the diverse D- and L-AAs in urine will be of high interest. Parameters reflecting the metabolomic profiles of the gut microbiota, the source of food intake and the biological systems of living species in general, for example are not yet fully explored sources of information related to health and disease statuses.

A most challenging area is the sensitive enantioselective analysis of the variety of AAs in complex matrices, which can currently be approached best with $2 \mathrm{D}$ concepts of $N$-tagged AA derivatives together with fluorescence and/or MS/MS detection. For free AAs, 2D concepts have not yet been established, and in this case MS detection seems the only option to reach high sensitivity and specificity. From a chromatographic aspect the introduction of very efficient UHPLC-type chiral columns using CSPs based on fully porous particles of sub-2- $\mu \mathrm{m}$ size or on partially porous particles (core shell particles) is emerging $[28,93]$, boosting the peak capacity of a column and reducing the overall analysis time. This is also of significance for the engineering of fully automated 2D-UPHPLC systems. 1D- and 2D-SFC systems for the analysis of biological samples have not yet been described and it remains to be seen how quickly the SFC technology will enter this field.

An upcoming challenge will be the resolution of peptide enantiomers and stereoisomers. The latter should in principle be accomplishable by RP chromatography, though complementary selective chromatographic systems will be needed to solve the problem comprehensively. 
CSPs may meet such demands very well. 2D systems will have the greatest flexibility in this context, whereby the mobile phase compatibility of both dimensions is a crucial factor to be dealt with.

To solve these challenges efficiently in the near future, the combinations of RP and macrocyclic or ion-exchange-type CSP systems appear most promising.

In summary, the aim of our discussion of the recently published enantioselective methodologies to resolve free and tagged AAs was to provide an overview of the technical and practical solutions. Insight into molecular recognition has been integrated. There is clearly room for further advances of the applied methodologies to solve the current and future challenges based on "stateof-the-art" enantioseparations. The development of new and novel CSPs still makes sense.

\section{Acknowledgments}

This work was supported by Hungarian National Science Foundation grant OTKA K 108847. 


\section{References}

[1] G.K.E. Scriba, Differentiation of enantiomers by capillary electrophoresis, Topics in Curr. Chem. 340 (2013) 209-276.

[2] G.K.E. Scriba, Chiral recognition in separation sciences: an overview, in: G.K.E. Scriba (Ed.), Chiral separations, Methods in Molecular Biology, Humana Press, 970 (2013) 1-27.

[3] V. Defontaine, D. Guillarme, E. Francotte, L. Nováková, Supercritical fluid chromatography in pharmaceutical analysis, J. Pharm. Biomed. Anal. (2015) DOI: 10.1016/j.jpba.2015.03.007.

[4] S. Tanwar, R. Bhushan, Enantioresolution of amino acids: a decade's perspective, prospects and challenges, Chromatographia, (2015) DOI: 10.1007/s10337-015-2933-8.

[5] E. Francotte, Chiral stationary phases for preparative enantioselective chromatography, in: G.B Cox (Ed.), Preparative Enantioselective Chromatography, Wiley-Blackwell, (2007) 48-77.

[6] S. Batra, R. Bhushan, Amino acids as chiral auxiliaries in cyanuric chloride-based chiral derivatizing agents for enantioseparation by liquid chromatography, Biomed. Chromatogr. 28 (2014) 1532-1564.

[7] I. Ilisz, A. Aranyi, Péter, Chiral derivatizations applied for the separation of unusual amino acid enantiomers by liquid chromatography and related techniques, J. Chromatogr. A 1296 (2013) 119-139.

[8] I. Ilisz, A. Aranyi, Z. Pataj, A. Péter, Enantiomeric separation of nonproteinogenic amino acids by high-performance liquid chromatography, J. Chromatogr. A, 1269 (2012) 94-121.

[9] I. Ilisz, A. Aranyi, Z. Pataj, A. Péter, Recent advances in the direct and indirect liquid chromatographic enantioseparation of amino acids and related compounds: A review, J. Pharm. Biomed. Anal. 69 (2012) 28-41. 
[10] R. Bhushan, H. Brückner, Use of Marfey's reagent and analogs for chiral amino acid analysis: Assessment and applications to natural products and biological systems, J. Chromatogr. B-Anal. Techn. Biomed. Life Sci. 879 (2011) 3148-3161.

[11] R. Bhushan, C. Agarwal, Application of (S)-N-(4-nitrophenoxycarbonyl) phenylalanine methoxyethyl ester as a chiral derivatizing reagent for reversed-phase high-performance liquid chromatographic separation of diastereomers of amino alcohols, non-protein amino acids, and PenA, Amino Acids 39 (2010) 549-554.

[12] B. Brucher, J. Rudat, C. Syldatk, O. Vielhauer, Enantioseparation of aromatic $\beta^{3}$-amino acid by precolumn derivatization with o-phthaldialdehyde and $N$-isobutyryl-L-cysteine, Chromatographia 71 (2010) 1063-1067.

[13] K. Karthikeyan, G.T. Arularasu, R. Ramadhas, K.C. Pillai, Development and validation of indirect RP-HPLC method for enantiomeric purity determination of D-cycloserine drug substance, J. Pharm. Biomed. Anal. 54 (2011) 850-854.

[14] R. Bhushan, H. Nagar, Indirect enantioseparation of selenomethionine by reversed-phase high-performance liquid chromatography using a newly synthesized chiral derivatizing reagent based on (S)-naproxen moiety, Biomed. Chromatogr. 28 (2014) 101-116.

[15] R. Bhushan, H. Nagar, Indirect enantioseparation of proteinogenic amino acids using naproxen-based chiral derivatizing reagent and HPLC, Biomed. Chromatogr. 27 (2013) 750-756. [16] R. Bhushan, R. Dubey, Synthesis of $(S)$-naproxen-benzotriazole and its application as chiral derivatizing reagent for microwave-assisted synthesis and indirect high performance liquid chromatographic separation of diastereomers of penicillamine, cysteine and homocysteine, J. Chromatogr. A 1218 (2011) 3648-3652. 
[17] R. Bhushan, R. Dubey, Validated high-performance liquid chromatographic enantioseparation of selenomethionine using isothiocyanate based chiral derivatizing reagents, Biomed. Chromatogr. 26 (2012) 471-478.

[18] R. Bhushan, M. Lal, LC Enantioseparation of 30-component diastereomeric mixture of amino acids and detection of D-isomers using new reagents with amines as chiral auxiliaries in cyanuric chloride, Chromatographia 76 (2013) 1087-1096.

[19] R. Bhushan, S. Dixit, Application of cyanuric chloride-based six new chiral derivatizing reagents having amino acids and amino acid amides as chiral auxiliaries for enantioresolution of proteinogenic amino acids by reversed-phase high-performance liquid chromatography, Amino Acids 42 (2012) 1371-1378.

[20] R. Bhushan, R. Dubey, Application of amino acid amides as chiral auxiliaries in difluoro dinitro benzene and cyanuric chloride moieties for high-performance liquid-chromatographic enantioseparation of selenomethionine and its mixture with methionine and cysteine, Amino Acids 42 (2012) 1417-1423.

[21] D.W. Armstrong, Y. Tang, S. Chen, Y. Zhou, C. Bagwill, J.R. Chen, Macrocyclic antibiotics as a new class of chiral selectors for liquid chromatography, Anal. Chem. 66 (1994) 1473-1484.

[22] M.A. Kuznetsov, P.N. Nesterenko, G.G. Vasiyarov, S.M. Staroverov, High-performance liquid chromatography of $\alpha$-amino acid enantiomers on eremomycin-modified silica, J. Anal. Chem. 63 (2008) 57-64.

[23] L. Sipos, I. Ilisz, M. Nonn, F. Fülöp, Z. Pataj, D.W. Armstrong, A. Péter, High-performance liquid chromatographic enantioseparation of unusual isoxazoline-fused 2aminocyclopentanecarboxylic acids on macrocyclic glycopeptide-based chiral stationary phases, J. Chromatogr. A, 1232 (2012) 142-151. 
[24] L. Sipos, I. Ilisz, Z. Pataj, Z. Szakonyi, F. Fülöp, D.W. Armstrong, A. Péter, Highperformance liquid chromatographic enantioseparation of monoterpene-based 2-amino carboxylic acids on macrocyclic glycopeptide-based phases, J. Chromatogr. A 1217 (2010) 6956-6963.

[25] Z. Pataj, I. Ilisz, N. Grecso, M. Palko, F. Fülöp, D.W. Armstrong, A. Péter, Enantiomeric separation of bicyclo[2.2.2] octane-based 2-amino-3-carboxylic acids on macrocyclic glycopeptide chiral stationary phases, Chirality 26 (2014) 200-208.

[26] G. Kucerova, J. Vozka, K. Kalikova, R. Geryk, D. Plecita, T. Pajpanova, E. Tesarova, Enantioselective separation of unusual amino acids by high performance liquid chromatography, Sep. Pur. Techn. 119 (2013) 123-128.

[27] R. Sardella, F. Ianni, A. Lisanti, S. Scorzoni, F. Marini, S. Sternativo, B. Natalini, Direct chromatographic enantioresolution of fully constrained $\beta$-amino acids: exploring the use of highmolecular weight chiral selectors, Amino Acids 46 (2014) 1235-1242.

[28] D.C. Patel, Z.S. Breitbach, M.F. Wahab, C.L. Barhate, D.W. Armstrong, Gone in seconds: praxis, performance, and peculiarities of ultrafast chiral liquid chromatography with superficially porous particles, Anal. Chem. (2015) DOI: 10.1021/acs.analchem.5b00715

[29] I. Ilisz, Z. Pataj, R. Berkecz, A. Misicka, D. Tymecka, F. Fülöp, H.J. Choi, M.H. Hyun, A. Péter, High-performance liquid chromatographic enantioseparation of $\beta^{2}$-amino acids using a long-tethered (+)-(18-crown-6)-2,3,11,12-tetracarboxylic acid-based chiral stationary phase, J. Chromatogr. A 1217 (2010) 1075-1082.

[30] L. Sipos, I. Ilisz, A. Aranyi, Z. Gecse, M. Nonn, F. Fülöp, M.H. Hyun, A. Péter, Highperformance liquid chromatographic enantioseparation of unusual isoxazoline-fused 2aminocyclopentanecarboxylic acids on (+)-(18-crown-6)-2,3,11,12-tetracarboxylic acid-based chiral stationary phases, Chirality 24 (2012) 817-824. 
[31] H.J. Choi, H.S. Cho, S.J. Lee, M.H. Hyun, Liquid chromatographic resolution of vigabatrin and its analogue $\gamma$-amino acids on chiral stationary phases based on (3,3'-diphenyl-1,1'binaphthyl)-20-crown-6, Bull. Kor. Chem. Soc. 32 (2011) 3017-3021.

[32] S.A. Ahn, M.H. Hyun, Liquid chromatographic resolution of amino acid esters of acyclovir including racemic valacyclovir on crown ether-based chiral stationary phases, Chirality 27 (2015) 268-263.

[33] V.A. Davankov, S.V. Rogozhin, Ligand chromatography as a novel method for the investigation of mixed complexes: stereoselective effects in amino acid copper (II) complexes, J. Chromatogr. 60 (1971) 280-283.

[34] B. Natalini, N. Giacche, R. Sardella, F. Ianni, A. Macchiarulo, R. Pellicciari, Computational studies for the elucidation of the enantiomer elution order of amino acids in chiral ligandexchange chromatography, J. Chromatogr. A 1217 (2010) 7523-7527.

[35] Z. Gecse, I. Ilisz, M. Nonn, N. Grecso, F. Fülöp, R. Agneeswari, M.H. Hyun, A. Péter, High-performance liquid chromatographic enantioseparation of isoxazoline-fused 2aminocyclopentanecarboxylic acids on a chiral ligand-exchange stationary phase, J. Sep. Sci. 36 (2013) 1335-1342.

[36] R. Sardella, A. Lisanti, M. Marinozzi, F. Ianni, B. Natalini, G. Patricia Blanch, M. L. Ruiz del Castillo, Combined monodimensional chromatographic approaches to monitor the presence of D-amino acids in cheese, Food Cont. 34 (2013) 478-484.

[37] C.V. Hoffmann, R. Pell, M. Lämmerhofer, W. Lindner, Synergistic effects on enantioselectivity of zwitterionic chiral stationary phases for separations of chiral acids, bases, and amino acids by HPLC, Anal. Chem. 80 (2008) 8780-8789. 
[38] R. Pell, S. Sic, W. Lindner, Mechanistic investigations of cinchona alkaloid-based zwitterionic chiral stationary phases, J. Chromatogr. A 1269 (2012) 287-296.

[39] Z. Pataj, I. Ilisz, Z. Gecse, Z. Szakonyi, F. Fülöp, W. Lindner, A. Péter, Effect of mobile phase composition on the liquid chromatographic enantioseparation of bulky monoterpene-based beta-amino acids by applying chiral stationary phases based on Cinchona alkaloid, J. Sep. Sci. 37 (2014) 1075-1082.

[40] I. Ilisz, Z. Pataj, Z. Gecse, Z. Szakonyi, F. Fülöp, W. Lindner, A. Péter, Unusual temperature-induced retention behavior of constrained beta-amino acid enantiomers on the zwitterionic chiral stationary phases ZWIX(+) and ZWIX(-), Chirality 26 (2014) 385-393.

[41] I. Ilisz, N. Grecso, A. Aranyi, P. Suchotin, D. Tymecka, B. Wilenska, A. Misicka, F. Fülöp, W. Lindner, A. Péter, Enantioseparation of $\beta^{2}$-amino acids on cinchona alkaloid-based zwitterionic chiral stationary phases. Structural and temperature effects, J. Chromatogr. A 1334 (2014) 44-54.

[42] I. Ilisz, N. Grecso, M. Palko, F. Fülöp, W. Lindner, A. Péter, Structural and temperature effects on enantiomer separations of bicyclo[2.2.2] octane-based 3-amino-2-carboxylic acids on cinchona alkaloid-based zwitterionic chiral stationary phases, J. Pharm. Biomed. Anal. 98 (2014) 130-139.

[43] T. Zhang, E. Holder, P. Franco, W. Lindner, Method development and optimization on cinchona and chiral sulfonic acid-based zwitterionic stationary phases for enantiomer separations of free amino acids by high-performance liquid chromatography, J. Chromatogr. A 1363 (2014) 191-199.

[44] I. Ilisz, Z. Gecse, Z. Pataj, F. Fülöp, G. Toth, W. Lindner, A. Péter, Direct high-performance liquid chromatographic enantioseparation of secondary amino acids on Cinchona alkaloid-based 
chiral zwitterionic stationary phases. Unusual temperature behavior, J. Chromatogr. A 1363 (2014) 169-177.

[45] I. Ilisz, Z. Gecse, G. Lajko, M. Nonn, F. Fülöp, W. Lindner, A. Péter, Investigation of the structure-selectivity relationships and van't Hoff analysis of chromatographic stereoisomer separations of unusual isoxazoline-fused 2-aminocyclopentanecarboxylic acids on Cinchona alkaloid-based chiral stationary phases, J. Chromatogr. A 1384 (2015) 67-75. [46] I. Ilisz, N. Grecso, A. Misicka, D. Tymecka, L. Lázár, W. Lindner, A. Péter, Comparison of the separation performances of cinchona alkaloid-based zwitterionic stationary phases in the enantioseparation of $\beta^{2}$ - and $\beta^{3}$-amino acids, Molecules 20 (2015) 70-87.

[47] D. Wang, J. Zhao, H. Wu, H. Wu, J. Cai, Y. Ke, X. Liang, Preparation and evaluation of novel chiral stationary phases based on quinine derivatives comprising crown ether moieties, J. Sep. Sci. 38 (2015) 205-210.

[48] S. Wernisch, W. Lindner, Versatility of cinchona-based zwitterionic chiral stationary phases: Enantiomer and diastereomer separations of non-protected oligopeptides utilizing a multi-modal chiral recognition mechanism, J. Chromatogr. A 1269 (2012) 297-304.

[49] S. Wernisch, O. Trapp, W. Lindner, Application of cinchona-sulfonate-based chiral zwitterionic ion exchangers for the separation of proline-containing dipeptide rotamers and determination of on-column isomerization parameters from dynamic elution profiles, Anal. Chim. Acta 795 (2013) 88-98.

[50] T. Zhang, E. Holder, P. Franco, W. Lindner, Zwitterionic chiral stationary phases based on cinchona and chiral sulfonic acids for the direct stereoselective separation of amino acids and other amphoteric compounds, J. Sep. Sci. 37 (2014) 1237-1247. 
[51] F. Ianni, R. Sardella, A. Carotti, B. Natalini, W. Lindner, M. Lämmerhofer, Quinine-based zwitterionic chiral stationary phase as complementary tool for peptide analysis: mobile phase effects on enantio- and stereoselectivity of underivatized oligopeptides, Chirality (2015) in press

[52] M. Kotake, T. Sakan, N. Nakamura, S. Senoh, Resolution into optical isomers of some amino acids by paper chromatography, J. Am. Chem. Soc. 73 (1951) 2973-2974.

[53] Y. Okamoto, M. Kawashima, K. Hatada, Useful chiral packing materials for highperformance liquid chromatographic resolution of enantiomers: phenylcarbamates of polysaccharide coated on silicagel, J. Am. Chem. Soc. 106 (1984) 5357-5359.

[54] T. Zhang, P. Franco, D. Nguyen, R. Hamasaki, S. Miyamoto, A. Ohnishi, T. Murakami, Complementary enantiorecognition patterns and specific method optimization aspects on immobilized polysaccharide-derived chiral stationary phases, J. Chromatogr. A 1269 (2012). $178-188$.

[55] E. Dominguez-Vega, A.L. Crego, K. Lomsadze, B. Chankvetadze, M.L. Marina, Enantiomeric separation of FMOC-amino acids by nano-LC and CEC using a new chiral stationary phase, cellulose tris(3-chloro-4-methylphenylcarbamate), Electrophoresis 32 (2011) 2700-2707.

[56] H. Huang, W.J. Xu, J.-Y. Jin, J.H. Hong, H.-J. Shin, W. Lee, A convenient method for the enantiomeric separation of alpha-amino acid esters as benzophenone imine Schiff base derivatives, Arch. Pharm. Res. 35 (2012) 1015-1019.

[57] B.-H. Kim, S.U. Lee, D.C. Moon, Chiral recognition of $N$-phthaloyl, $N$-tetrachlorophthaloyl, and $N$-naphthaloyl $\alpha$-amino acids and their esters on polysaccharide-derived chiral stationary phases, Chirality 24 (2012) 1037-1046. 
[58] P. Fatas, A.M. Gil, M. Isabel Calaza, A.I. Jimenez, C. Cativiela, Access to enantiomerically pure cis- and trans- $\beta$-phenylproline by high-performance liquid chromatography resolution, Chirality 24 (2012) 1082-1091.

[59] J. Zhao, X. Lu, Y. Wang, J. Lv, 'Click' preparation of a novel 'native-phenylcarbamoylated' bilayer cyclodextrin stationary phase for enhanced chiral differentiation, J. Chromatogr. A 1381 (2015) 253-259.

[60] X. Yao, T.T.Y. Tan, Y. Wang, Thiol-ene click chemistry derived cationic cyclodextrin chiral stationary phase and its enhanced separation performance in liquid chromatography, J. Chromatogr. A 1326 (2014) 80-88.

[61] J. Zhao, X. Lu, Y. Wang, T.T.Y. Tan, Surface-up constructed tandem-inverted bilayer cyclodextrins for enhanced enantioseparation and adsorption, J. Chromatogr. A 1343 (2014) 101108.

[62] W.H. Pirkle, D.L. Sikkenga, Use of achiral shift-reagents to indicate relative stabilities of diastereomeric solvates, J. Org. Chem. 40 (1975) 3430-3434.

[63] M. Lämmerhofer, W. Lindner, Liquid chromatographic enantiomer separation and chiral recognition by cinchona alkaloid-derived enantioselective separation materials, in: E. Grushka, N. Grinberg (Eds.), Advances in Chromatography, CRC Press, Boca Raton, 46 (2008) 1-107.

[64] C.V. Hoffmann, M. Lämmerhofer, W. Lindner, Novel strong cation exchanger type chiral stationary phase for the enantiomer separation of chiral amines by HPLC, J. Chromatogr. A 1161 (2007) 242-251.

[65] K.M. Kacprzak, N.M. Maier, W. Lindner, Triazolo-linked cinchona alkaloid carbamate anion exchange-type chiral stationary phases: Synthesis by click chemistry and evaluation, J. Chromatogr. A 1218 (2011) 1452-1460. 
[66] S. Keunchkarian, J.M. Padro, J. Gotta, A.M. Nardillo, C.B. Castells, Synthesis and evaluation of a chiral stationary phase based on quinine: Enantioresolution of dinitrophenyl derivatives of $\alpha$-amino acids, J. Chromatogr. A 1218 (2011) 3660-3668.

[67] S. Keunchkarian, J.O. Grisales, J.M. Padro, S. Boeris, C.B. Castells, Development of a chiral stationary phase based on cinchonidine. Comparison with a quinine-based chiral column, Chirality 24 (2012) 512-518.

[68] S. Wernisch, F. Bisi, A.S. Cazzato, M. Kohout, W. Lindner, 2-Acyl-dimedones as UV-active protective agents for chiral amino acids: enantiomer separations of the derivatives on chiral anion exchangers, Anal. Bioanal. Chem. 405 (2013) 8011-8026.

[69] R. Hellinger, J. Horak, W. Lindner, Enantioseparation of 6-aminoquinolyl-Nhydroxysuccinimidyl carbamate tagged amino acids and other zwitterionic compounds on cinchona-based chiral stationary phases, Anal. Bioanal. Chem. 405 (2013) 8105-8120.

[70] Q. Wang, J. Feng, H. Han, P. Zhu, H. Wu, M. Luisa Marina, J. Crommen, Z. Jiang, Enantioseparation of $N$-derivatized amino acids by micro-liquid chromatography using carbamoylated quinidine functionalized monolithic stationary phase, J. Chromatogr. A 1363 (2014) 207-2015.

[71] T. Oyama, E. Negishi, H. Onigahara, N. Kusano, Y. Miyoshi, M. Mita, M. Nakazono, S. Ohtsuki, A. Ojida, W. Lindner, K. Hamase, Design and synthesis of a novel pre-column derivatization reagent with a 6-methoxy-4-quinolone moiety for fluorescence and tandem mass spectrometric detection and its application to chiral amino acid analysis, J. Pharm. Biomed. Anal. (2015) DOI: 10.1016/j.jpba.2015.05.039.

[72] F. Ianni, A. Carotti, M. Marinozzi, G. Marcelli, A.D. Michele, R. Sardella, W. Lindner, B. Natalini, Diastereo- and enantioseparation of a $N^{\alpha}$-Boc amino acid with a zwitterionic quinine- 
based stationary phase: focus on the stereorecognition mechanism, Anal. Chim. Acta (2015), DOI: 10.1016/j.aca.2015.06.001.

[73] Y. Xie, G.M. Alexander, R.J. Schwartzman, N. Singh, M.C. Torjman, M.E. Goldberg, I.W. Wainer, R. Moaddel, Development and validation of a sensitive LC-MS/MS method for the determination of D-serine in human plasma, J. Pharm. Biomed. Anal. 89 (2013) 1-5.

[74] H. Fleischer, K. Thurow, Fast mass spectrometry-based enantiomeric excess determination of proteinogenic amino acids, Amino Acids 44 (2013) 1039-1051.

[75] H. Iizuka, Y. Hirasa, K. Kubo, K. Ishii, T. Toyo'oka, T. Fukushima, Enantiomeric separation of D,L-tryptophan and D,L-kynurenine by HPLC using pre-column fluorescence derivatization with $R(-)-D B D-P y N C S$, Biomed. Chromatogr. 25 (2011) 743-747.

[76] H. Iizuka, K. Ishii, Y. Hirasa, K. Kubo, T. Fukushima, Fluorescence determination of D- and L-tryptophan concentrations in rat plasma following administration of tryptophan enantiomers using HPLC with pre-column derivatization, J. Chromatogr. B-Anal. Techn. Biomed. Life Sci. 879 (2011) 3208-3213.

[77] K. Inoue, D. Hosaka, N. Mochizuki, H. Akatsu, K. Tsutsumiuchi, Y. Hashizume, N. Matsukawa, T. Yamamoto, T. Toyo'oka, Simultaneous determination of post-translational racemization and isomerization of $N$-terminal amyloid- $\beta$ in Alzheimer's brain tissues by covalent chiral derivatized ultraperformance liquid chromatography tandem mass spectrometry, Anal. Chem. 86 (2014) 797-804.

[78] C. Mueller, J.R. Fonseca, T.M. Rock, S. Krauss-Etschmann, P. Schmitt-Kopplin, Enantioseparation and selective detection of D-amino acids by ultra-high-performance liquid chromatography/mass spectrometry in analysis of complex biological samples, J. Chromatogr. A 1324 (2014) 109-114. 
[79] K. Takada, A. Ninomiya, M. Naruse, Y. Sun, M. Miyazaki, Y. Nogi, S. Okada, S. Matsunaga, Surugamides A-E, Cyclic octapeptides with four D-amino acid residues, from a marine Streptomyces sp.: LC-MS-aided inspection of partial hydrolysates for the distinction of Dand L-amino acid residues in the sequence, J. Org. Chem. 78 (2013) 6746-6750.

[80] T. Mochizuki, K. Todoroki, K. Inoue, J.Z. Min, T. Toyo'oka, Isotopic variants of light and heavy L-pyroglutamic acid succinimidyl esters as derivatization reagents for DL-amino acid chiral metabolomics identification by liquid chromatography and electrospray ionization mass spectrometry, Anal. Chim. Acta 811 (2014) 51-59.

[81] W.F. Visser, N.M. Verhoeven-Duif, R. Ophoff, S. Bakker, L.W. Klomp, R. Berger, T.J. de Koning, A sensitive and simple ultra-high-performance-liquid chromatography-tandem mass spectrometry based method for the quantification of D-amino acids in body fluids, J. Chromatogr. A 1218 (2011) 7130-7136.

[82] T. Miyamoto, M. Sekine, T. Ogawa, M. Hidaka, H. Homma, H. Masaki, Generation of enantiomeric amino acids during acid hydrolysis of peptides detected by the liquid chromatography/tandem mass spectroscopy, Chem. \& Biodiversity 7 (2010) 1644-1650.

[83] K. Hamase, Y. Miyoshi, K. Ueno, H. Han, J. Hirano, A. Morikawa, M. Mita, T. Kaneko, W. Lindner, K. Zaitsu, Simultaneous determination of hydrophilic amino acid enantiomers in mammalian tissues and physiological fluids applying a fully automated micro-two-dimensional high-performance liquid chromatographic concept, J. Chromatogr. A 1217 (2010) 1056-1062.

[84] R. Koga, Y. Miyoshi, E. Negishi, T. Kaneko, M. Mita, W. Lindner, K. Hamase, Enantioselective two-dimensional high-performance liquid chromatographic determination of Nmethyl-D-aspartic acid and its analogues in mammals and bivalves, J. Chromatogr. A 1269 (2012) 255-261. 
[85] J. Sasabe, Y. Miyoshi, M. Suzuki, M. Mita, R. Konno, M. Matsuoka, K. Hamase, S. Aiso, DAmino acid oxidase controls motoneuron degeneration through D-serine, Proc. New York Acad. Sci. 109 (2012) 627-632.

[86] Y. Miyoshi, T. Oyama, Y. Itoh, K. Hamase, Enantioselective two-dimensional highperformance liquid chromatographic determination of amino acids; analysis and physiological significance of D-amino acids in mammals, Chromatography 35 (2014) 49-57.

[87] K. Hamase, Y. Nakauchi, Y. Miyoshi, R. Koga, N. Kusano, H. Onigahara, H. Naraoka, H. Mita, Y. Kadota, Y. Nishio, M. Mita, W. Lindner, Enantioselective determination of extraterrestrial amino acids using two-dimensional chiral high-performance liquid chromatographic system, Chromatography 35 (2014) 103-110.

[88] S. Karakawa, Y. Miyoshi, R. Konno, S. Koyanagi, M. Mita, S. Ohdo, K. Hamase, Twodimensional high-performance liquid chromatographic determination of day-night variation of Dalanine in mammals and factors controlling the circadian changes, Anal. Bioanal. Chem. 405 (2013) 8083-8091.

[89] H. Han, Q.-Q. Wang, H.-H. Wu, H. Wang, Establishment and application of an automated chiral two-dimensional high performance liquid chromatography method for bio-analysis of Dacidic amino acids, Chinese J. Anal. Chem. 42 (2014) 891-895.

[90] R.J. Reischl, L. Hartmanova, M. Carrozzo, M. Huszar, P. Fruehauf, W. Lindner, Chemoselective and enantioselective analysis of proteinogenic amino acids utilizing $N$ derivatization and 1-D enantioselective anion-exchange chromatography in combination with tandem mass spectrometric detection, J. Chromatogr. A 1218 (2011) 8379-8387.

[91] S. Karakawa, K. Shimbo, N. Yamada, T. Mizukoshi, H. Miyano, M. Mita, W. Lindner, K. Hamase, Simultaneous analysis of D-alanine, D-aspartic acid, and D-serine using chiral high- 
performance liquid chromatography-tandem mass spectrometry and its application to the rat plasma and tissues, J. Pharm. Biomed. Anal. (2015) Doi: 10.1016/j.jpba.2015.05.024

[92] K. Kinoshita, S. Jingu, J.-i. Yamaguchi, A surrogate analyte method to determine D-serine in mouse brain using liquid chromatography-tandem mass spectrometry, Anal. Biochem. 432 (2013) 124-130.

[93] L. Sciascera, O. Ismail, A. Ciogli, D. Kotoni, A. Cavazzini, L. Botta, T. Szczerba, J. Kocergin, C. Villani, F. Gasparrini, Expanding the potential of chiral chromatography for highthroughput screening of large compound libraries by means of sub-2 $\mu \mathrm{m}$ Whelk-O 1 stationary phase in supercritical fluid conditions, J. Chromatogr. A 1383 (2015) 160-168. 
Scheme 1

Several structures of investigated amino acids

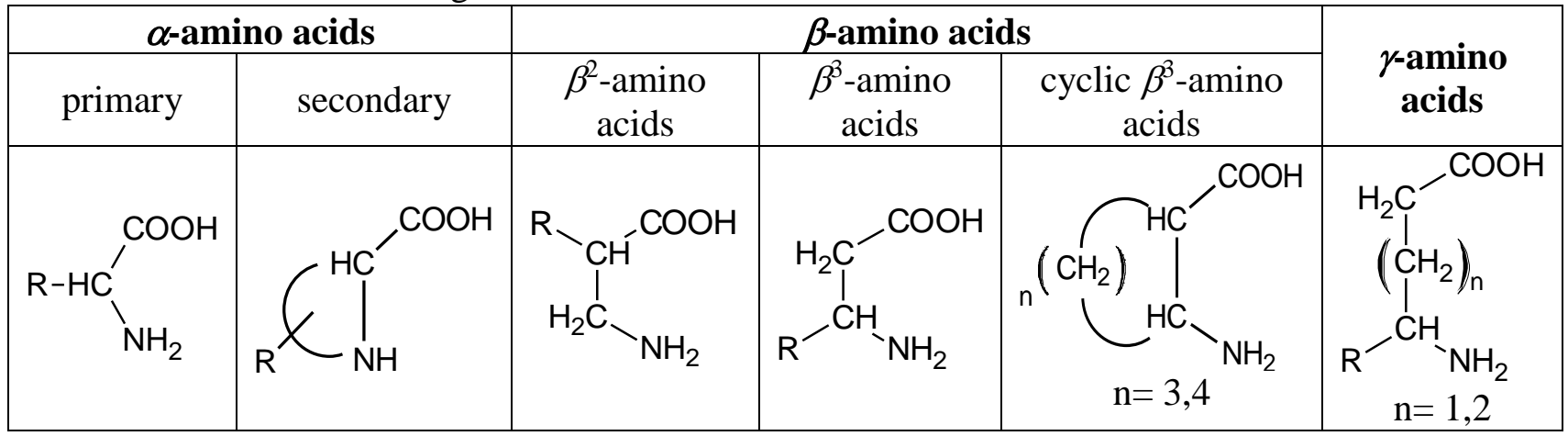

$\mathrm{R}_{1}$ : alkyl, cycloalkyl, aromatic, substituted aromatic, hetero aromatic $\mathrm{R}_{2}$ : H, alkyl 
Scheme 2 Structures of frequently used Tag elements and reagents

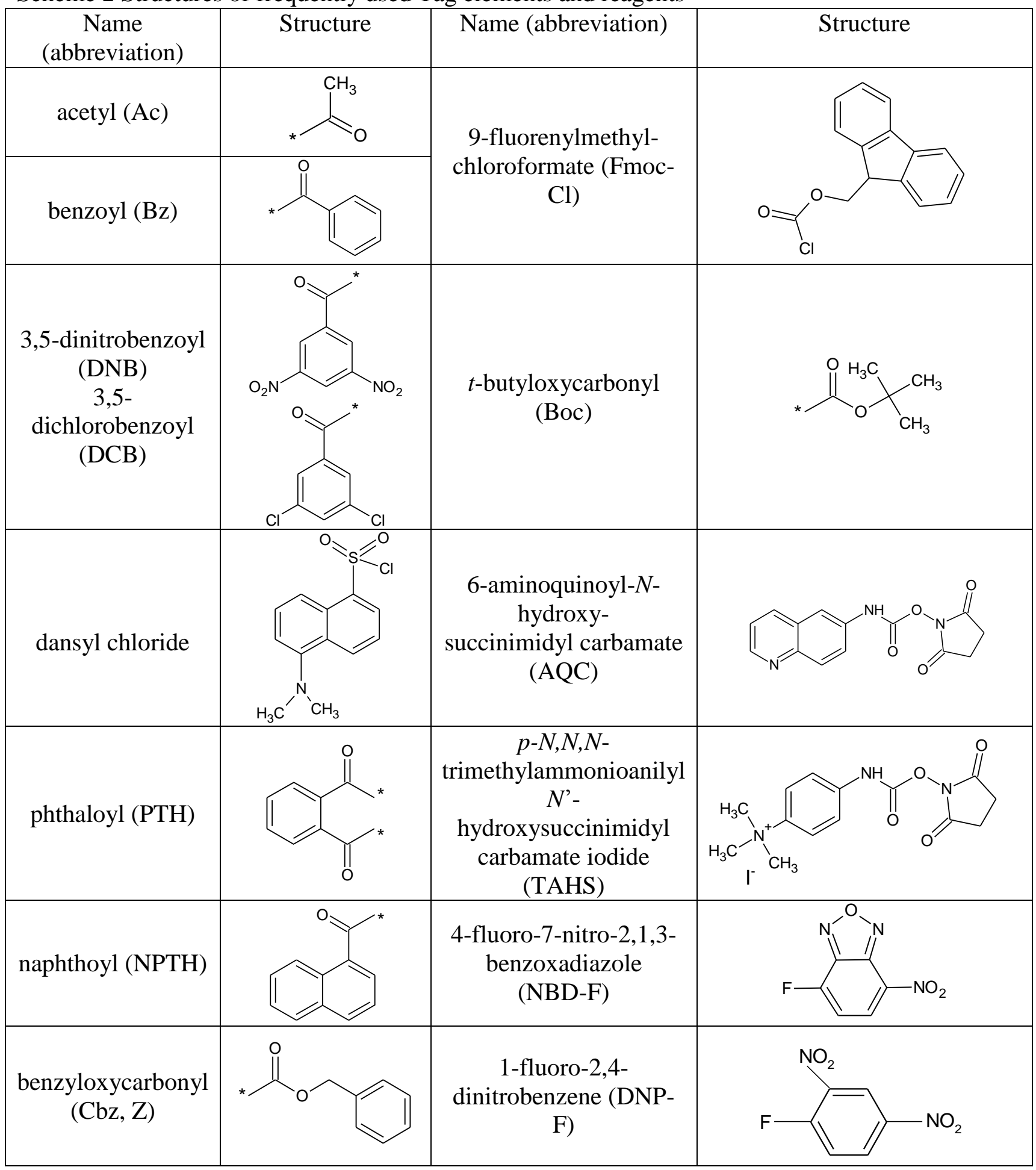


Table 1. Indirect methods: derivatization of amino group of amino acid enantiomers prior to separation by HPLC method

\begin{tabular}{|c|c|c|c|c|}
\hline Analytes & $\begin{array}{c}\text { Chiral derivatizing } \\
\text { agents } \\
\text { (CDAs) }\end{array}$ & $\begin{array}{l}\text { Chromatographic } \\
\text { conditions }\end{array}$ & Detection & References \\
\hline $\begin{array}{c}\text { Phg, Nva, 2- } \\
\text { aminoadipic acid, } \\
\text { 2-aminobutyric acid, } \\
\text { pipecolic acid, } \\
\text { 2-aminooctanoic } \\
\text { acid }\end{array}$ & $(S)$-NIFE & $\begin{array}{l}\text { Eurospher } \mathrm{C} 18 / \\
\text { aq. TFA-MeOH }\end{array}$ & $\mathrm{UV}, 205 \mathrm{~nm}$ & [11] \\
\hline$\beta$-Phe, $\beta$-Tyr & OPA/IBLC & $\begin{array}{l}\text { Hyperclone ODS/ } \\
\mathrm{Na}_{2} \mathrm{HPO}_{4}-\mathrm{MeOH}\end{array}$ & $\begin{array}{c}\mathrm{Fl}, \mathrm{Exc} / \mathrm{Em} \\
235 \mathrm{~nm} / \\
442 \mathrm{~nm}\end{array}$ & [12] \\
\hline D-cycloSer & OPA/NAC & $\begin{array}{l}\text { Zorbax SB phenyl/ } \\
\text { aq. } \mathrm{Na}_{2} \mathrm{HPO}_{4}-\mathrm{MeCN}\end{array}$ & $\mathrm{UV}, 335 \mathrm{~nm}$ & {$[13]$} \\
\hline $\mathrm{D}, \mathrm{L}$-selenoMet & $\begin{array}{c}\text { phthalimidyl- }(S)- \\
\text { naproxen }\end{array}$ & $\begin{array}{l}\text { Lichrospher C18/ } \\
\text { aq. TEAP/MeCN }\end{array}$ & $\mathrm{UV}, 231 \mathrm{~nm}$ & [14] \\
\hline $\begin{array}{l}18 \text { proteinogenic } \\
\text { D,L-amino acids }\end{array}$ & Nap-Btz & $\begin{array}{l}\text { Eurospher C18/ } \\
\text { aq. TEAP/MeCN }\end{array}$ & $\mathrm{UV}, 231 \mathrm{~nm}$ & {$[15]$} \\
\hline Cys, homoCys & Nap-Btz & $\begin{array}{l}\text { Spherisorb ODS/ } \\
\text { aq. TEAP/MeCN }\end{array}$ & $\mathrm{UV}, 231 \mathrm{~nm}$ & {$[16]$} \\
\hline D,L-selenoMet & MBIC and NEIC & $\begin{array}{l}\text { Spherisorb ODS-2/ } \\
\text { aq. TEAP/MeCN }\end{array}$ & $\mathrm{UV}, 254 \mathrm{~nm}$ & [17] \\
\hline $\begin{array}{l}\text { proteinogenic } \mathrm{D}, \mathrm{L}- \\
\text { amino acids }\end{array}$ & $\begin{array}{c}\text { monochloro-s-triazine } \\
\text { and dichloro-s-triazine } \\
\text { derivatives }\end{array}$ & $\begin{array}{l}\text { Eurospher } \mathrm{C} 18 \text { or } \\
\text { Lichrospher C18/ } \\
\text { aq. TFA/MeCN or } \\
\text { aq. TFA-MeOH }\end{array}$ & $\mathrm{UV}, 230 \mathrm{~nm}$ & {$[18,19]$} \\
\hline $\begin{array}{c}\text { D,L-selenoMet, } \\
\text { D,L-Met, D,L-Cys }\end{array}$ & $\begin{array}{c}\text { monochloro-s-triazine } \\
\text { and dichloro-s-triazine } \\
\text { derivatives }\end{array}$ & $\begin{array}{l}\text { Spherisorb ODS/ } \\
\text { aq. TFA/MeCN }\end{array}$ & $\mathrm{UV}, 230 \mathrm{~nm}$ & {$[20]$} \\
\hline
\end{tabular}


Table 2. Direct enantioselective high-performance liquid chromatographic determination of amino acids

\begin{tabular}{|c|c|c|c|c|}
\hline Analytes & $\begin{array}{c}\text { Chiral } \\
\text { stationary phase } \\
\text { (CSP) or } \\
\text { Selector }\end{array}$ & $\begin{array}{l}\text { Experimental } \\
\text { conditions/ } \\
\text { Eluent }\end{array}$ & Detection & References \\
\hline \multicolumn{5}{|c|}{ Macrocyclic glycopeptide-based CSPs } \\
\hline $\begin{array}{l}\text { monoterpene-based 2- } \\
\text { aminocarboxylic acid }\end{array}$ & $\begin{array}{l}\text { Chirobiotic T }{ }^{\mathrm{TM}} \text {, } \\
\mathrm{T}^{\mathrm{TM}}, \mathrm{TAG}^{\mathrm{TM}},\end{array}$ & $\begin{array}{l}\text { aq. TEAA-MeOH; } \\
\text { 100\% MeOH; } \\
\text { MeOH-AcOH- } \\
\text { TEA }\end{array}$ & $\begin{array}{l}\mathrm{UV}, 210 \\
\mathrm{~nm}\end{array}$ & {$[23]$} \\
\hline $\begin{array}{c}\text { isoxazoline fused 2- } \\
\text { aminocyclopentanecarboxylic } \\
\text { acid }\end{array}$ & $\begin{array}{l}\text { Chirobiotic } \mathrm{T}^{\mathrm{TM}}, \\
\mathrm{T}^{\mathrm{TM}}, \mathrm{TAG}^{\mathrm{TM}}, \mathrm{V}^{\mathrm{TM}} \\
\text { and } \mathrm{VAG}^{\mathrm{TM}}\end{array}$ & $\begin{array}{l}\text { aq. TEAA-MeOH; } \\
100 \% \mathrm{MeOH}\end{array}$ & $\begin{array}{l}\mathrm{UV}, 210 \\
\mathrm{~nm}\end{array}$ & [24] \\
\hline $\begin{array}{l}\text { bicycle[2.2.2]octane based 2- } \\
\text { amino-3-carboxylic acids }\end{array}$ & $\begin{array}{l}\text { Chirobiotic } \mathrm{T}^{\mathrm{TM}}, \\
\mathrm{T}^{\mathrm{TM}}, \mathrm{TAG}^{\mathrm{TM}}, \mathrm{R}^{\mathrm{TM}}\end{array}$ & $\begin{array}{c}\text { aq. TEAA-MeOH; } \\
\text { MeOH-AcOH- } \\
\text { TEA; } \\
\text { MeOH-MeCN- } \\
\text { AcOH-TEA }\end{array}$ & $\begin{array}{l}\mathrm{UV}, 215 \\
\mathrm{~nm}\end{array}$ & {$[25]$} \\
\hline unusual amino acids & $\begin{array}{l}\text { Chirobiotic } \mathrm{T}^{\mathrm{TM}} \\
\text { and } \mathrm{T} 2^{\mathrm{TM}}\end{array}$ & $\begin{array}{l}\text { aq. } \mathrm{NH}_{4} \mathrm{OAc}- \\
\mathrm{MeOH}\end{array}$ & $\begin{array}{l}\text { UV. } 254 \\
\mathrm{~nm}\end{array}$ & {$[26]$} \\
\hline$\beta$-amino acids & Chirobiotic $\mathrm{T}^{\mathrm{TM}}$ & $\begin{array}{c}\mathrm{H}_{2} \mathrm{O}-\mathrm{MeOH} \\
\mathrm{H}_{2} \mathrm{O}-\mathrm{EtOH}\end{array}$ & $\begin{array}{l}\mathrm{UV}, 220 \\
\mathrm{~nm}\end{array}$ & {$[27]$} \\
\hline $\begin{array}{l}\text { proteinogenic and unusual amino } \\
\text { acids }\end{array}$ & $\begin{array}{c}\text { teicoplanin and } \\
\text { teicoplanin aglycon } \\
\text { on } \\
2.7 \mu \mathrm{m} \\
\text { superficially porous } \\
\text { silica }\end{array}$ & $\mathrm{H}_{2} \mathrm{O}-\mathrm{MeOH}$ & UV, DAD & {$[28]$} \\
\hline \multicolumn{5}{|c|}{ Crown ether-based CSPs } \\
\hline$\beta^{2}$-amino acids & $\begin{array}{c}(+)-(18 \text {-crown-6)- } \\
2,3,11,12- \\
\text { tetracarboxylic acid }\end{array}$ & $\mathrm{H}_{2} \mathrm{O}-\mathrm{MeOH}$-acid & $\begin{array}{l}\mathrm{UV}, 205 \\
\mathrm{~nm}\end{array}$ & {$[29]$} \\
\hline $\begin{array}{c}\text { isoxazoline fused } 2- \\
\text { aminocyclopentanecarboxylic } \\
\text { acid }\end{array}$ & $\begin{array}{c}(+)-(18-\text { crown-6)- } \\
\text { 2,3,11,12- } \\
\text { tetracarboxylic acid }\end{array}$ & $\begin{array}{c}\mathrm{H}_{2} \mathrm{O}-\mathrm{MeOH}- \\
\mathrm{AcOH} \\
\mathrm{H}_{2} \mathrm{O} \text {-alcohol-acid }\end{array}$ & $\begin{array}{l}\mathrm{UV}, 205 \\
\mathrm{~nm}\end{array}$ & {$[30]$} \\
\hline$\gamma$-amino acids, vigabatrin & $\begin{array}{l}\text { (3,3'-diphenyl-1, } 1^{\prime} \text { - } \\
\text { binaphthyl)- } \\
\text { 20-crown-6 }\end{array}$ & $\begin{array}{c}\mathrm{H}_{2} \mathrm{O}-\mathrm{MeOH}- \\
\mathrm{H}_{2} \mathrm{SO}_{4}-\mathrm{NH}_{4} \mathrm{OAc}\end{array}$ & $\begin{array}{l}\mathrm{UV}, 251 \\
\mathrm{~nm}\end{array}$ & {$[31]$} \\
\hline
\end{tabular}


Table 2. (continued) Direct enantioselective high-performance liquid chromatographic determination of amino acids

\begin{tabular}{|c|c|c|c|c|}
\hline Analytes & $\begin{array}{c}\text { Chiral stationary } \\
\text { phase } \\
\text { (CSP) or Selector }\end{array}$ & $\begin{array}{l}\text { Experimental } \\
\text { conditions } \\
\text { Eluent }\end{array}$ & Detection & References \\
\hline \multicolumn{5}{|c|}{ Crown ether-based CSPs } \\
\hline acyclovir, valacyclovir & $\begin{array}{l}\text { (3,3'-diphenyl-1,1'- } \\
\text { binaphthyl)- } \\
\text { 20-crown-6 }\end{array}$ & $\begin{array}{r}\mathrm{H}_{2} \mathrm{O}-\mathrm{MeOH}-\mathrm{HCl} \\
\mathrm{H}_{2} \mathrm{O} \text {-alcohol-ac }\end{array}$ & $\begin{array}{l}\mathrm{UV}, 254 \\
\mathrm{~nm}\end{array}$ & [32] \\
\hline & $\begin{array}{l}\text { Chiral ligand- } \\
\text { exchange } \\
\text { chromatography }\end{array}$ & & & \\
\hline $\begin{array}{l}\text { protein and non-protein amino } \\
\text { acids }\end{array}$ & $(S)$-OBS & $\mathrm{H}_{2} \mathrm{O}-\mathrm{Cu}(\mathrm{II})$ & $\begin{array}{l}\mathrm{UV}, 254 \\
210 \mathrm{~nm}\end{array}$ & {$[34]$} \\
\hline $\begin{array}{l}\text { isoxazoline fused 2- } \\
\text { aminocyclopentanecarboxylic } \\
\text { acid }\end{array}$ & $\begin{array}{c}\text { sodium } N-((R)-2- \\
\text { hydroxy-1- } \\
\text { phenylethyl)- } N- \\
\text { undecylamino acetate }\end{array}$ & $\begin{array}{r}\mathrm{H}_{2} \mathrm{O}-\mathrm{MeOH}-\mathrm{Cu}( \\
\mathrm{H}_{2} \mathrm{O}-\mathrm{EtOH}-\mathrm{Cu}(]\end{array}$ & $\begin{array}{l}\mathrm{UV}, 230 \\
\mathrm{~nm}\end{array}$ & [35] \\
\hline D-Ala, D-Asp, D-Glu & L-STC & $\begin{array}{l}\text { aq. HFBA- } \\
\text { MeCN-Cu(II) }\end{array}$ & ELSD & {$[36]$} \\
\hline \multicolumn{5}{|c|}{ Cinchona alkaloid-based CSPs } \\
\hline $\begin{array}{l}\text { proteinogenic and non- } \\
\text { proteinogenic amino acids }\end{array}$ & $\begin{array}{c}\text { zwitterionic QN- and } \\
\text { QD derivatives }\end{array}$ & $\begin{array}{l}\text { MeOH-MeCN- } \\
\text { FA-DEA }\end{array}$ & $\begin{array}{l}\mathrm{UV}, 254 \\
\mathrm{~nm} ; \\
\mathrm{CAD}\end{array}$ & {$[38]$} \\
\hline $\begin{array}{l}\text { monoterpene-based cyclic } \beta^{3} \text { - } \\
\text { amino acids }\end{array}$ & $\begin{array}{l}\mathrm{ZWIX}(+)^{\mathrm{TM}} \text { and } \\
\text { ZWIX }(-)^{\mathrm{TM}}\end{array}$ & $\begin{array}{l}\mathrm{MeOH}-\mathrm{MeCN}- \\
\text { acid-amine }\end{array}$ & $\begin{array}{l}\mathrm{UV}, 215 \\
\mathrm{~nm} ; \\
\mathrm{CAD}\end{array}$ & {$[39,40]$} \\
\hline$\beta^{2}$-amino acids & $\begin{array}{l}\mathrm{ZWIX}(+)^{\mathrm{TM}} \text { and } \\
\mathrm{ZWIX}(-)^{\mathrm{TM}}\end{array}$ & $\begin{array}{l}\mathrm{MeOH}-\mathrm{MeCN}- \\
\text { acid-amine }\end{array}$ & $\begin{array}{l}\mathrm{UV}, 215 \\
\mathrm{~nm} ; \\
\mathrm{CAD}\end{array}$ & [41] \\
\hline $\begin{array}{l}\text { Bicyclo[2.2.2]octane-based 3- } \\
\text { amino-2-carboxylic acid }\end{array}$ & $\begin{array}{l}\mathrm{ZWIX}(+)^{\mathrm{TM}} \text { and } \\
\mathrm{ZWIX}(-)^{\mathrm{TM}}\end{array}$ & $\begin{array}{l}\mathrm{MeOH}-\mathrm{MeCN}- \\
\text { acid-amine }\end{array}$ & $\begin{array}{l}\mathrm{UV}, 215 \\
\mathrm{~nm} ; \\
\mathrm{CAD}\end{array}$ & [42] \\
\hline $\begin{array}{l}27 \text { unusual secondary amino } \\
\text { acids }\end{array}$ & $\begin{array}{l}\mathrm{ZWIX}(+)^{\mathrm{TM}} \text { and } \\
\operatorname{ZWIX}(-)^{\mathrm{TM}}\end{array}$ & $\begin{array}{l}\mathrm{MeOH}-\mathrm{MeCN}- \\
\text { acid-amine }\end{array}$ & $\begin{array}{l}\mathrm{UV}, 230 \\
254 \mathrm{~nm} \\
\mathrm{CAD}\end{array}$ & [44] \\
\hline
\end{tabular}


Table 2. (continued) Direct enantioselective high-performance liquid chromatographic determination of amino acids and small peptide epimers

\begin{tabular}{|c|c|c|c|c|}
\hline Analytes & $\begin{array}{c}\text { Chiral } \\
\text { stationary phase } \\
\text { (CSP) or } \\
\text { Selector } \\
\end{array}$ & $\begin{array}{l}\text { Experimental } \\
\text { conditions } \\
\text { Eluent }\end{array}$ & Detection & References \\
\hline $\begin{array}{c}\text { isoxazoline-fused } 2- \\
\text { aminocyclopentanecarboxylic } \\
\text { acids }\end{array}$ & $\begin{array}{l}\mathrm{ZWIX}(+)^{\mathrm{TM}} \text { and } \\
\mathrm{ZWIX}(-)^{\mathrm{TM}}\end{array}$ & $\begin{array}{l}\mathrm{MeOH}-\mathrm{MeCN} \text {-acid- } \\
\text { amine }\end{array}$ & $\begin{array}{l}\mathrm{UV}, 215 \\
230 \mathrm{~nm} \\
\text { CAD }\end{array}$ & {$[45]$} \\
\hline$\beta^{2}$ - and $\beta^{3}$-amino acids & $\begin{array}{l}\mathrm{ZWIX}(+)^{\mathrm{TM}} \text { and } \\
\operatorname{ZWIX}(-)^{\mathrm{TM}}\end{array}$ & $\begin{array}{l}\mathrm{MeOH}-\mathrm{MeCN} \text {-acid- } \\
\text { amine }\end{array}$ & $\begin{array}{l}\mathrm{UV}, 215 \\
230 \mathrm{~nm} \\
\text { CAD }\end{array}$ & {$[46]$} \\
\hline $\begin{array}{l}\text { proteinogenic and non- } \\
\text { proteinogenic amino acids }\end{array}$ & $\begin{array}{l}\text { QN modified by } \\
\text { meta- or para- } \\
\text { substituted benzo- } \\
\text { 18-crown-6 }\end{array}$ & $\begin{array}{l}\mathrm{MeOH}-\mathrm{FA}-\mathrm{DEA} ; \\
\mathrm{MeOH}-\mathrm{H}_{2} \mathrm{O}-\mathrm{FA}- \\
\text { DEA; } \mathrm{MeOH}-\mathrm{FA}- \\
\text { DEA-NH}{ }_{4} \mathrm{OAc} ; \text { etc. }\end{array}$ & & [47] \\
\hline \multicolumn{5}{|c|}{ Separation of small peptide epimers } \\
\hline all-L/all-D, Ala-n, Phe-n, Val-n & $\begin{array}{l}\text { cinchona- } \\
\text { sulfonate-based } \\
\text { CSP }\end{array}$ & $\begin{array}{l}\text { MeOH-FA-DEA } \\
\text { aq. TFA-MeCN }\end{array}$ & CAD & {$[48]$} \\
\hline $\begin{array}{l}\text { D-Pro-D-Pro, D-Pro-L-Pro, L- } \\
\text { Pro-D-Pro, } \\
\text { L-Pro-L-Pro, Gly-D-Pro, D-Pro- } \\
\text { Gly }\end{array}$ & $\begin{array}{l}\text { cinchona- } \\
\text { sulfonate-based } \\
\text { CSP }\end{array}$ & $\mathrm{MeOH}-\mathrm{FA}-\mathrm{DEA}$ & CAD & [49] \\
\hline $\begin{array}{l}\text { D,L-Leu-D,L-Ala; D,L-Leu-D,L- } \\
\text { Val }\end{array}$ & $\begin{array}{l}\mathrm{ZWIX}(+)^{\mathrm{TM}} \text { and } \\
\operatorname{ZWIX}(-)^{\mathrm{TM}}\end{array}$ & $\mathrm{MeOH}-\mathrm{MeCN}-\mathrm{H}_{2} \mathrm{O}$ & & {$[50]$} \\
\hline $\begin{array}{l}\text { Gly-D,L-Leu-D,L-Ala; D,L-Leu- } \\
\text { D,L-Ala-Gly }\end{array}$ & & $\begin{array}{c}\text { MeOH-THF- } \mathrm{H}_{2} \mathrm{O} \\
\mathrm{MeOH}-\mathrm{H}_{2} \mathrm{O}\end{array}$ & & \\
\hline $\begin{array}{c}\text { Leu-Leu, Leu-Leu-Leu; Gly- } \\
\text { Asn; Gly-Asp } \\
\text { Gly-Ser }\end{array}$ & $\mathrm{ZWIX}(+)^{\mathrm{TM}}$ & $\begin{array}{l}\text { MeOH-MeCN-FA- } \\
\text { DEA } \\
\text { MeOH-THF- FA- } \\
\text { DEA }\end{array}$ & CAD & {$[51]$} \\
\hline
\end{tabular}

acid: AcOH, FA; amine: EA, DEA, TEA, PA, TPA, BA, TBA; alcohol: MeOH, EtOH, 2-propanol 
Table 3. Direct methods: separation of tagged amino acid enantiomers by HPLC method on different types of CSPs

\begin{tabular}{|c|c|c|c|c|}
\hline Analytes & $\begin{array}{l}\text { Derivatizing } \\
\text { agents } \\
\text { (DA) }\end{array}$ & $\begin{array}{l}\text { Chromatographic conditions } \\
\text { column or selector/eluent }\end{array}$ & Detection & References \\
\hline \multicolumn{5}{|c|}{ Polysaccharide-based CSPs } \\
\hline $\begin{array}{l}\text { proteinogenic and } \\
\text { non proteinogenic } \\
\text { amino acids }\end{array}$ & FMOC & 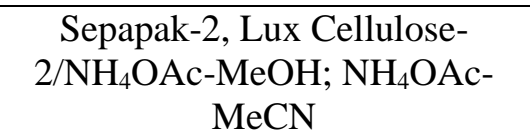 & $\begin{array}{c}\mathrm{UV}, 210 \\
\text { and } 260 \mathrm{~nm}\end{array}$ & {$[55]$} \\
\hline $\begin{array}{l}\text { Ala, Asp, Asn, Leu, } \\
\text { Phe, Phg, Val }\end{array}$ & $\begin{array}{l}\text { benzophenone } \\
\text { imine }\end{array}$ & $\begin{array}{c}\text { Chiralcel OD, Chiralpak AD, } \\
\text { AS/2-propanol-hexane }\end{array}$ & $\mathrm{UV}, 254 \mathrm{~nm}$ & {$[56]$} \\
\hline $\begin{array}{l}\text { Ala, Val, Leu, Ile, } \\
\text { Phg, Phe }\end{array}$ & $\begin{array}{l}N \text {-PTH, } N- \\
\text { TCPHT, } N- \\
\quad \text { NPHT }\end{array}$ & $\begin{array}{c}\text { Chiralcel OC, OD, OF, OJ, AD, } \\
\text { AS; Chiralpak AD, AS/2- } \\
\text { propanol-hexane }\end{array}$ & $\mathrm{UV}, 230 \mathrm{~nm}$ & [57] \\
\hline $\begin{array}{l}\text { cis/trans- } \beta \text { - } \\
\text { phenylPro }\end{array}$ & Boc & $\begin{array}{c}\text { Chiralpak IA,IB,IC/hexane- } \\
\text { 2-PrOH-CHCl }{ }_{3} \text { (acetone, } \\
t \text {-BuOMe) }\end{array}$ & $\begin{array}{l}\mathrm{UV}, 210 \text { or } \\
230 \mathrm{~nm}\end{array}$ & {$[58]$} \\
\hline \multicolumn{5}{|c|}{$\beta$-cyclodextrin-based CSPs } \\
\hline $\begin{array}{l}\text { Nva, Val, Leu, Phe, } \\
\text { Ser, Thr }\end{array}$ & Dns & $\begin{array}{c}\text { perphenylcarbamoylated- } \beta- \\
\mathrm{CD} / \mathrm{H}_{2} \mathrm{O}-\mathrm{MeOH}, \\
\text { aq. TEAA-MeOH }\end{array}$ & $\begin{array}{l}\mathrm{UV}, 220- \\
230 \mathrm{~nm}\end{array}$ & [59] \\
\hline $\begin{array}{l}\text { Thr, Nva, Val, Nle, } \\
\text { Leu, Phe, Glu }\end{array}$ & Dns & $\begin{array}{l}\text { imidazolium } \beta-\mathrm{CD} / \\
\text { aq. TEAA-MeOH }\end{array}$ & $\begin{array}{l}\mathrm{UV}, 220- \\
230 \mathrm{~nm}\end{array}$ & {$[60]$} \\
\hline $\begin{array}{l}\text { Nva, Val, Leu, Phe, } \\
\text { Ser, Thr }\end{array}$ & Dns & $\begin{array}{l}\text { triazole bridged bilayer } \\
\beta \text {-CD/aq. TEAA-MeCN }\end{array}$ & $\begin{array}{l}\mathrm{UV}, 220- \\
230 \mathrm{~nm}\end{array}$ & {$[61]$} \\
\hline
\end{tabular}

Table 3. (continued) Direct methods: separation of tagged amino acid enantiomers by HPLC method on different types of CSPs

\begin{tabular}{|c|c|c|c|c|}
\hline Analytes & $\begin{array}{c}\text { Derivatizing agents } \\
\text { (DA) }\end{array}$ & $\begin{array}{c}\text { Chromatographic } \\
\text { conditions } \\
\text { column or } \\
\text { selector/eluent }\end{array}$ & Detection & References \\
\hline
\end{tabular}

Ion-exchange type CSPs

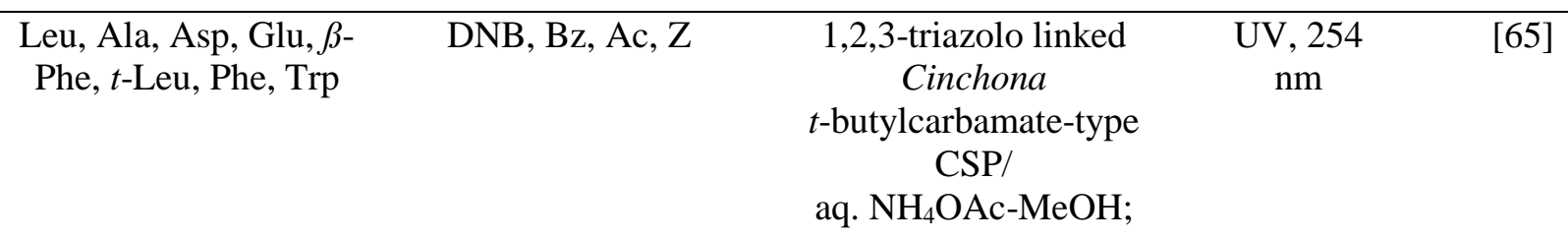




\begin{tabular}{|c|c|c|c|c|}
\hline & & $\mathrm{MeCN}-\mathrm{AcOH}-\mathrm{TEA}$ & & \\
\hline $\begin{array}{l}20 \text { proteinogenic and } \\
\text { non-proteinogenic } \\
\text { amino acids }\end{array}$ & 2,4-DNP & $\begin{array}{c}\text { Cinchonidine- and QN- } \\
\text { based CSP/ } \\
\text { /aq. } \mathrm{NH}_{4} \mathrm{OAc}-\mathrm{MeOH} \\
\mathrm{NH}_{4} \mathrm{OAc}-\mathrm{MeCN}\end{array}$ & $\begin{array}{l}\mathrm{UV}, 365 \\
\mathrm{~nm}\end{array}$ & {$[66,67]$} \\
\hline $\begin{array}{l}\text { proteinogenic amino } \\
\text { acids, 2- and 3- } \\
\text { aminobutyric acid }\end{array}$ & 2-acyl-dimedone & $\begin{array}{c}\mathrm{MeOH}-\mathrm{FA}-\mathrm{DEA} ; \mathrm{MeOH}- \\
\mathrm{MeCN}-\mathrm{FA}-\mathrm{DEA} ; \mathrm{MeOH}- \\
\mathrm{H}_{2} \mathrm{O}-\mathrm{AcOH}-\mathrm{NH}_{4} \mathrm{OAc}\end{array}$ & $\begin{array}{l}\mathrm{UV}, 254 \\
\mathrm{~nm}\end{array}$ & [68] \\
\hline $\begin{array}{c}\text { Ile, Thr, homoSer, 4- } \\
\text { OH-Pro, } \beta \text {-amino } \\
\text { acids, Phe derivatives, } \\
\text { etc. }\end{array}$ & AQC & $\begin{array}{c}\text { QN-AX, QD-AX/ } \\
\text { MeOH-AcOH-NH} 4 \mathrm{OAc} ; \\
\text { aq. } \mathrm{NH}_{4} \mathrm{OAc}-\mathrm{MeOH}\end{array}$ & $\begin{array}{c}\mathrm{Fl}, \mathrm{Ex} / \mathrm{Em} \\
248 / 395 \mathrm{~nm}\end{array}$ & [69] \\
\hline $\begin{array}{l}\text { Ala, Leu, Met, Thr, } \\
\text { Phe, Val, Ser, Ile, Trp } \\
\text { and Cys }\end{array}$ & $\begin{array}{c}\text { 3,5-DNB, 3,5-DCB, } \\
\text { 3,5-DCIB, } \\
\text { FMOC, etc. }\end{array}$ & MQD & $\begin{array}{l}\mathrm{UV}, 254 \\
\mathrm{~nm}\end{array}$ & {$[70]$} \\
\hline $\begin{array}{l}\text { proteinogenic amino } \\
\text { acids }\end{array}$ & $\begin{array}{l}\text { 2,5-dioxopyrrolidin-1- } \\
\text { yl(2-(6-methoxy-4- } \\
\text { oxoquinolin-1(4H)- } \\
\text { yl)ethyl) carbonate }\end{array}$ & $\begin{array}{c}\text { ZWIX }(+)^{\mathrm{TM}} \text {, Chiralpak } \\
\text { QN-AX MeOH-MeCN- } \\
\text { FA- } \mathrm{HCOONH}_{4}\end{array}$ & $\begin{array}{l}\mathrm{MS} / \mathrm{MS} \\
\mathrm{CAD}\end{array}$ & [71] \\
\hline $\begin{array}{c}\mathrm{N}^{\alpha}-\text { Boc- } \mathrm{N}^{4}- \\
\text { (hydroorotyl)-4- } \\
\text { aminophenylalanine }\end{array}$ & Boc & $\begin{array}{c}\text { ZWIX }(+)^{\mathrm{TM}}, \text { ZWIX(- } \\
\text { ) }^{\mathrm{TM}} / \mathrm{MeOH}-\mathrm{MeCN}-\mathrm{FA}- \\
\text { DEA }\end{array}$ & $\begin{array}{l}\mathrm{UV}, 254 \\
\mathrm{~nm}\end{array}$ & [72] \\
\hline
\end{tabular}


Table 4. Determination of chiral amino acids in biological and natural samples by HPLC methods

\begin{tabular}{|c|c|c|c|c|c|}
\hline Analytes & Sources/Matrixes & $\begin{array}{c}\text { Chiral } \\
\text { derivatizing } \\
\text { agents } \\
\text { (CDAs) } \\
\end{array}$ & $\begin{array}{l}\text { Experimental } \\
\text { conditions } \\
\text { Column/eluent }\end{array}$ & Detection & References \\
\hline \multicolumn{6}{|c|}{ Indirect methods: application of CDA and non-chiral selector } \\
\hline $\begin{array}{c}\text { D,L-selenoMet, } \\
\text { D,L-Met, D,L-Cys }\end{array}$ & & $\begin{array}{c}(R) \text {-1-Boc-2- } \\
\text { piperidine } \\
\text { carbonyl } \\
\text { chloride }\end{array}$ & $\begin{array}{c}\text { Zorbax Eclipse } \\
\text { XDB C18/aq. TFA- } \\
\text { MeOH }\end{array}$ & $\begin{array}{c}\text { LC- } \\
\text { MS/MS }\end{array}$ & [73] \\
\hline $\begin{array}{l}19 \text { chiral } \\
\text { proteinogenic } \\
\text { amino acids }\end{array}$ & Marfey's reagent & $\begin{array}{l}\text { Marfey's } \\
\text { reagent }\end{array}$ & $\begin{array}{c}\text { Zorbax SB-C18/aq. } \\
\text { FA-MeCN }\end{array}$ & HPLC-MS & [74] \\
\hline Trp, kynurenine & rat plasma & $\begin{array}{l}R(-)-\mathrm{DBD}- \\
\text { PyNCS }\end{array}$ & $\begin{array}{l}\text { Inertsil ODS-3/ } \\
\text { aq. AcOH-MeCN, } \\
\text { aq. FA-MeCN }\end{array}$ & $\begin{array}{l}\text { Fl, Ex/em, } \\
440 \\
\mathrm{~nm} / 565 \mathrm{~nm}\end{array}$ & [75] \\
\hline $\operatorname{Trp}$ & rat plasma & (-)-DBD-PyNCS & $\begin{array}{l}\text { Inertsil ODS-3/ } \\
\text { aq. AcOH-MeCN }\end{array}$ & $\begin{array}{c}\text { Fl, Ex/em, } \\
440 \\
\mathrm{~nm} / 565 \mathrm{~nm}\end{array}$ & [76] \\
\hline L,D-Asp, L,D-isoAsp & $\begin{array}{l}\text { human brain } \\
\text { tissue }\end{array}$ & $\begin{array}{l}R(-)-\mathrm{DBD}- \\
\text { PyNCS }\end{array}$ & $\begin{array}{l}\text { BEH C18/aq. FA- } \\
\text { MeOH }\end{array}$ & $\begin{array}{l}\text { UPLC- } \\
\text { MS/MS }\end{array}$ & {$[77]$} \\
\hline $\begin{array}{l}\text { proteinogenic } \mathrm{D}, \mathrm{L}- \\
\text { amino acids }\end{array}$ & $\begin{array}{l}\text { serum, plasma, } \\
\text { urine, gut }\end{array}$ & OPA/IBLC & $\begin{array}{l}\text { BEH C18/aq. } \\
\text { NaOAc-MeCN- } \\
\text { MeOH }\end{array}$ & $\begin{array}{l}\text { LC- } \\
\text { TOF- } \\
\text { MS }\end{array}$ & [78] \\
\hline $\begin{array}{c}\text { Phe, Leu, Ala, Ile, } \\
\text { Lys }\end{array}$ & $\begin{array}{l}\text { Surugamides } \\
\text { A-E, cyclic } \\
\text { octapeptide }\end{array}$ & GITC, FDAA & $\begin{array}{c}\text { Cosmosil C-18/aq. } \\
\text { AcOH-MeCN }\end{array}$ & $\begin{array}{c}\text { LC- } \\
\text { MS/MS }\end{array}$ & [79] \\
\hline $\begin{array}{l}18 \text { proteolytic amino } \\
\text { acids }\end{array}$ & $\begin{array}{l}\text { human serum, } \\
\text { food products }\end{array}$ & L-PGA-OSU & $\begin{array}{l}\text { BEH C18/ aq. FA- } \\
\text { MeCN }\end{array}$ & $\begin{array}{c}\text { LC- } \\
\text { MS/MS }\end{array}$ & {$[80]$} \\
\hline $\begin{array}{l}\text { proteinogenic D- } \\
\text { amino acids }\end{array}$ & $\begin{array}{c}\text { human plasma, } \\
\text { cerebrospinal, } \\
\text { urine }\end{array}$ & $(S)$-NIFE & $\begin{array}{c}\text { BEH C18/aq. } \\
\mathrm{NH}_{4} \mathrm{HCO}_{3}-\mathrm{MeCN}\end{array}$ & $\begin{array}{l}\text { UPLC- } \\
\text { MS/MS }\end{array}$ & {$[81]$} \\
\hline
\end{tabular}


Table 4. (continued) Determination of chiral amino acids in biological and natural samples by HPLC methods

\begin{tabular}{|c|c|c|c|c|c|}
\hline Analytes & Sources/Matrixes & $\begin{array}{c}\text { Non-chiral } \\
\text { derivatizing } \\
\text { agents }\end{array}$ & $\begin{array}{l}\text { Experimental } \\
\text { conditions } \\
\text { Column/eluent }\end{array}$ & Detection & References \\
\hline \multicolumn{6}{|c|}{ Direct methods: application of non-chiral derivatizing agent and chiral selector } \\
\hline Ala, Phe & D-Phe ${ }^{2,6}-\mathrm{LHRH}$ & NBD-F & $\begin{array}{c}\text { Chirobiotic } \\
\text { TAG/aq- TFA- } \\
\text { MeOH }\end{array}$ & $\begin{array}{c}\text { LC- } \\
\mathrm{MS} / \mathrm{MS}\end{array}$ & [82] \\
\hline $\begin{array}{l}\text { His, Ser, Asn, } \\
\text { Gln, Arg, Asp, } \\
\text { allo-Thr, Glu, } \\
\text { Thr }\end{array}$ & $\begin{array}{l}\text { rat cerebrum, } \\
\text { plasma, urine }\end{array}$ & NBD-F & $\begin{array}{c}\text { 2D-HPLC; 1D, } \\
\text { monolithic ODS, } \\
\text { aq. TFA-MeCN; } \\
\text { 2D, Sumichiral } \\
\text { OA/aq. citric } \\
\text { acid-MeOH- } \\
\text { MeCN }\end{array}$ & $\begin{array}{c}\text { Fl, Ex/Em } \\
470 \\
\mathrm{~nm} / 530 \\
\mathrm{~nm}\end{array}$ & [83] \\
\hline $\begin{array}{l}N-M e-D-A s p \\
\text { N-Me-D-Glu }\end{array}$ & Wistar rats & NBD-F & $\begin{array}{c}\text { 2D-HPLC; 1D, } \\
\text { monolithic ODS, } \\
\text { aq. TFA-MeCN; } \\
\text { 2D, Sumichiral } \\
\text { OA/aq. citric } \\
\text { acid-MeOH- } \\
\text { MeCN }\end{array}$ & $\begin{array}{c}\text { LC- } \\
\text { MS/MS }\end{array}$ & {$[84]$} \\
\hline D-Ser, D-Ala & $\begin{array}{l}\text { mouse lumbar } \\
\text { spinal cords }\end{array}$ & NBD-F & $\begin{array}{l}\text { 2D-HPLC; 1D, } \\
\text { C18 } \\
\text { 2D, Sumichiral } \\
\text { OA }\end{array}$ & $\begin{array}{c}\mathrm{Fl}, \mathrm{Ex} / \mathrm{Em} \\
470 / 530 \\
\mathrm{~nm}\end{array}$ & [85] \\
\hline $\begin{array}{l}\text { D-Asp, D-Glu, } \\
\text { D-Pro, D-Arg, } \\
\text { D-Asn, D-Gln, } \\
\text { D-Glu, D-His, } \\
\text { D-Ser, D-Thr, } \\
\text { D-allo-Thr }\end{array}$ & mammals tissue & NBD-F & $\begin{array}{c}\text { 2D-HPLC; 1D, } \\
\text { monolithic ODS, } \\
\text { aq. TFA-MeCN; } \\
\text { 2D, Sumichiral } \\
\text { OA or Chiralpak } \\
\text { QN-AX }\end{array}$ & $\begin{array}{c}\mathrm{Fl}, \mathrm{Ex} / \mathrm{Em} \\
470 \\
\mathrm{~nm} / 530 \\
\mathrm{~nm}\end{array}$ & {$[86]$} \\
\hline $\begin{array}{c}\text { Ala, Val, 2- } \\
\text { aminobutyric } \\
\text { acid, Nva, } N- \\
\text { MeAla, isoVal, } \\
\text { 3- } \\
\text { aminoisobutyric } \\
\text { acid }\end{array}$ & $\begin{array}{l}\text { extraterrestrial } \\
\text { amino acids in } \\
\text { meteorite }\end{array}$ & NBD-F & $\begin{array}{c}\text { 2D-HPLC; 1D, } \\
\text { monolithic ODS, } \\
\text { aq. TFA-MeCN; } \\
\text { 2D, Sumichiral } \\
\text { OA, aq. FA- } \\
\text { MeCN }\end{array}$ & $\begin{array}{c}\text { Fl, Ex/Em } \\
470 \\
\mathrm{~nm} / 530 \\
\mathrm{~nm}\end{array}$ & [87] \\
\hline D-Ala & blood of Wistar rat & NBD-F & $\begin{array}{l}\text { 2D-HPLC; 1D, } \\
\text { microbore ODS/ } \\
\text { 2D, Sumichiral }\end{array}$ & $\begin{array}{c}\text { Fl, Ex/Em } \\
470 \\
\mathrm{~nm} / 530\end{array}$ & {$[88]$} \\
\hline
\end{tabular}


Table 4. (continued) Determination of chiral amino acids in biological and natural samples by HPLC methods

\begin{tabular}{|c|c|c|c|c|c|}
\hline Analytes & Sources/Matrixes & $\begin{array}{c}\text { Non-chiral } \\
\text { derivatizing } \\
\text { agents } \\
\end{array}$ & $\begin{array}{l}\text { Experimental } \\
\text { conditions } \\
\text { Column/eluent }\end{array}$ & Detection & References \\
\hline \multicolumn{6}{|c|}{ Direct methods: application of non-chiral derivatizing agent and chiral selector } \\
\hline D-Asp & $\begin{array}{l}\text { thymus and spleen } \\
\text { of mice }\end{array}$ & NBD-F & $\begin{array}{l}\text { 2D-HPLC; 1D, } \\
\text { monolith } \\
\text { ODS/aq, TFA- } \\
\text { MeCN } \\
\text { 2D, QD- } \\
\text { AX/citric acid- } \\
\text { MeOH-MeCN }\end{array}$ & $\begin{array}{c}\mathrm{Fl}, \mathrm{Ex} / \mathrm{Em} \\
470 \\
\mathrm{~nm} / 530 \\
\mathrm{~nm}\end{array}$ & [89] \\
\hline $\begin{array}{l}\text { proteinogenic } \\
\text { amino acids }\end{array}$ & human urine & SFP & $\begin{array}{l}\text { QN-AX and } \\
\text { QD-AX; aq. } \\
\mathrm{NH}_{4} \mathrm{COOH}- \\
\mathrm{MeOH}, \mathrm{FA}- \\
\quad \mathrm{MeOH}\end{array}$ & LC-MS & {$[90]$} \\
\hline $\begin{array}{l}\text { D-Ala, D-Asp, } \\
\text { D-Ser }\end{array}$ & $\begin{array}{l}\text { rat plasma and } \\
\text { tissues }\end{array}$ & AQC, TAHS & ZWIX $(+)$ & $\begin{array}{c}\mathrm{LC}- \\
\mathrm{MS} / \mathrm{MS}\end{array}$ & {$[91]$} \\
\hline \multicolumn{6}{|c|}{ Direct methods: application of CSPs } \\
\hline D-Ser & mouse brain & - & $\begin{array}{c}\text { Crownpak } \\
\text { CR(+)/aq. TFA- } \\
\text { MeOH }\end{array}$ & $\begin{array}{c}\text { LC- } \\
\text { MS/MS }\end{array}$ & [92] \\
\hline
\end{tabular}

